\title{
Cloud feedback mechanisms and their representation in global climate models
}

Article

Accepted Version

Ceppi, P., Brient, F., Zelinka, M. D. and Hartmann, D. L. (2017) Cloud feedback mechanisms and their representation in global climate models. WIREs Climate Change, 8 (4). e465. ISSN 1757-7799 doi: https://doi.org/10.1002/wcc.465 Available at https://centaur.reading.ac.uk/69900/

It is advisable to refer to the publisher's version if you intend to cite from the work. See Guidance on citing.

To link to this article DOI: http://dx.doi.org/10.1002/wcc.465

Publisher: Wiley

All outputs in CentAUR are protected by Intellectual Property Rights law, including copyright law. Copyright and IPR is retained by the creators or other copyright holders. Terms and conditions for use of this material are defined in the End User Agreement.

\section{www.reading.ac.uk/centaur}

\section{CentAUR}

Central Archive at the University of Reading

Reading's research outputs online 


\section{WIREs Wiley Interdiscipininary Reviews}

Article Title:

Cloud feedback mechanisms and their representation in global climate models

Article Type:

Advanced Review 


\section{Authors:}

\section{Paulo Ceppi}

Department of Meteorology, University of Reading, Reading, United Kingdom p.ceppi@reading.ac.uk

\section{Florent Brient}

Centre National de Recherches Météorologiques, Météo-France/CNRS, Toulouse, France Mark D. Zelinka

Cloud Processes Research Group, Lawrence Livermore National Laboratory, Livermore, United States

Dennis L. Hartmann

Department of Atmospheric Sciences, University of Washington, Seattle, United States 


\section{Abstract}

Cloud feedback - the change in top-of-atmosphere radiative flux resulting from the cloud response to warming - constitutes by far the largest source of uncertainty in the climate response to $\mathrm{CO}_{2}$ forcing simulated by global climate models (GCMs). We review the main mechanisms for cloud feedbacks, and discuss their representation in climate models and the sources of inter-model spread. Global-mean cloud feedback in GCMs results from three main effects: (1) rising freetropospheric clouds (a positive longwave effect); (2) decreasing tropical low cloud amount (a positive shortwave effect); (3) increasing high-latitude low cloud optical depth (a negative shortwave effect). These cloud responses simulated by GCMs are qualitatively supported by theory, high-resolution modeling, and observations. Rising high clouds are consistent with the Fixed Anvil Temperature (FAT) hypothesis, whereby enhanced upper-tropospheric radiative cooling causes anvil cloud tops to remain at a nearly fixed temperature as the atmosphere warms. Tropical low cloud amount decreases are driven by a delicate balance between the effects of vertical turbulent fluxes, radiative cooling, large-scale subsidence, and lower-tropospheric stability on the boundary-layer moisture budget. High-latitude low cloud optical depth increases are dominated by phase changes in mixedphase clouds. The causes of inter-model spread in cloud feedback are discussed, focusing particularly on the role of unresolved parameterized processes such as cloud microphysics, turbulence, and convection.

\section{Graphical/Visual Abstract and Caption}

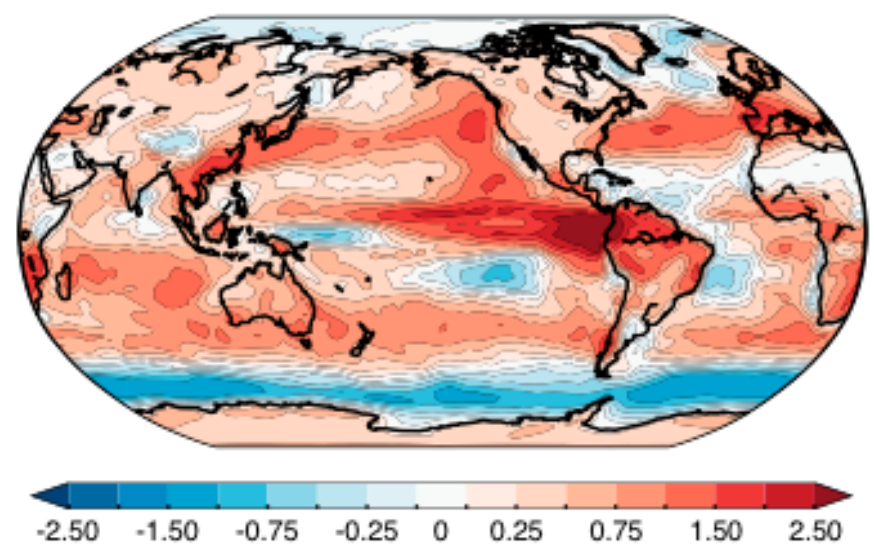

Spatial distribution of cloud feedback (in $\mathrm{W} \mathrm{m}^{-2}$ per $\mathrm{K}$ surface warming) predicted by a set of global climate models subjected to an abrupt increase in $\mathrm{CO}_{2}$. Redrawn with permission from Zelinka et al. (2016). 
3 As the atmosphere warms under greenhouse gas forcing, global climate models (GCMs) predict that 4 clouds will change, resulting in a radiative feedback by clouds ${ }^{1,2}$. While this cloud feedback is 5 positive in most GCMs and hence acts to amplify global warming, GCMs diverge substantially on its magnitude ${ }^{3}$. Accurately simulating clouds and their radiative effects has been a long-standing challenge for climate modeling, largely because clouds depend on small-scale physical processes that cannot be explicitly represented by coarse GCM grids. In the recent Climate Model Intercomparison Project phase 5 (CMIP5) ${ }^{4}$, cloud feedback was by far the largest source of inter-model spread in equilibrium climate sensitivity, the global-mean surface temperature response to $\mathrm{CO}_{2}$ doubling ${ }^{5-7}$. The important role of clouds in determining climate sensitivity in GCMs has been known for decades $^{8-11}$, and despite improvements in the representation of cloud processes ${ }^{12}$, much work remains to be done to narrow the range of GCM projections.

Despite these persistent difficulties, recent advances in our understanding of the fundamental mechanisms of cloud feedback have opened exciting new opportunities to improve the representation of the relevant processes in GCMs. Thanks to increasing computing power, turbulence-resolving model simulations have offered novel insight into the processes controlling marine low cloud cover ${ }^{13-16}$, of key importance to Earth's radiative budget ${ }^{17}$. Clever combined use of model hierarchies and observations has provided new understanding of why high-latitude clouds brighten ${ }^{18-20}$, why tropical anvil clouds shrink with warming ${ }^{21}$, and how clouds and radiation respond to storm track shifts ${ }^{22-24}$, to name a few examples.

The goal of this review is to summarize the current understanding of cloud feedback mechanisms, and to evaluate their representation in contemporary GCMs. Although the observational support for GCM cloud responses is assessed, we do not provide a thorough review of observational estimates of cloud feedback, nor do we discuss possible "emergent constraints" 25 . The discussion is organized into two main sections. First, we diagnose cloud feedback in GCMs, identifying the cloud property changes responsible for the radiative response. Second, we interpret these GCM cloud responses, discussing the physical mechanisms at play and the ability of GCMs to represent them, and briefly reviewing the available observational evidence. Based on this discussion, we conclude with suggestions for progress toward an improved representation of cloud feedback in climate models.

\section{DIAGNOSING CLOUD FEEDBACK IN GLOBAL CLIMATE MODELS}

We begin by documenting the magnitude and spatial structure of cloud feedback in contemporary GCMs, and identify the cloud property changes involved in the radiative response. Although clouds may respond to any forcing agent, in this review we will focus on cloud feedback to $\mathrm{CO}_{2}$ forcing, of highest relevance to future anthropogenic climate change.

\section{Global-mean cloud feedback}

The global-mean cloud feedback strength (quantified by the feedback parameter; Box 1 ) is plotted in Fig. 1, along with the other feedback processes included in the traditional decomposition. The feedback parameters are derived from CMIP5 experiments forced with abrupt quadrupling of $\mathrm{CO}_{2}$ concentrations relative to pre-industrial conditions. In the following discussion we quote the 

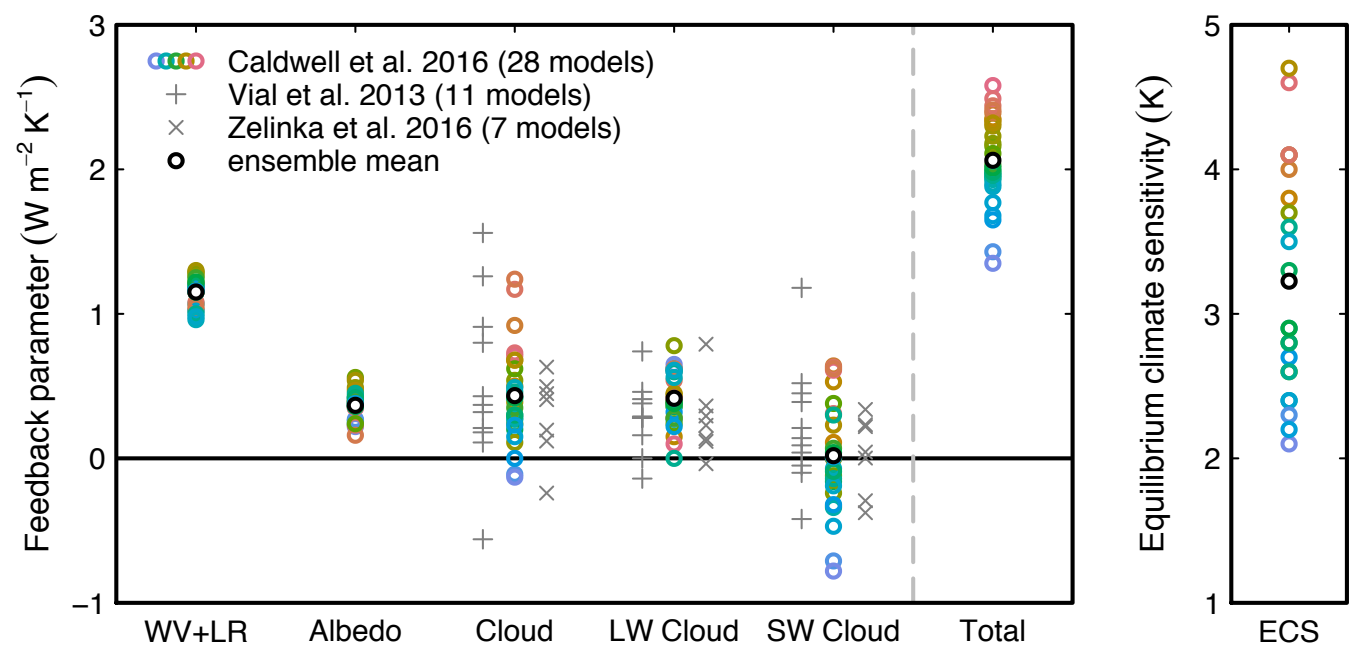

Fig. 1. Strengths of individual global-mean feedbacks and equilibrium climate sensitivity (ECS) for CMIP5 models, derived from coupled experiments with abrupt quadrupling of $\mathrm{CO}_{2}$ concentration. Model names and feedback values are listed in the Supporting Information, Table S1. Feedback parameter results are from Caldwell et al. ${ }^{5}$, with additional cloud feedback values from Vial et al. ${ }^{6}$ and Zelinka et al. ${ }^{26}$ ECS values are taken from Andrews et al. ${ }^{27}$, Forster et al. ${ }^{28}$, and Flato et al. ${ }^{29}$ Feedback parameters are calculated as in Soden et al. ${ }^{30}$ but accounting for rapid adjustments; the cloud feedback from Zelinka et al. is calculated using cloud-radiative kernels $^{31}$ (Box 2). Circles are colored according to the total feedback parameter. The Planck feedback (mean value of $-3.15 \mathrm{~W} \mathrm{~m}^{-2} \mathrm{~K}^{-1}$ ) is excluded from the total feedback parameter shown here.

Box 1: Climate feedbacks

Increasing greenhouse gas concentrations cause a positive radiative forcing $F\left(\mathrm{~W} \mathrm{~m}^{-2}\right)$, to which the climate system responds by increasing its temperature to restore radiative balance according to

$$
N=F+\lambda \Delta T
$$

$N$ denotes the net energy flux imbalance at the top of atmosphere, and $\Delta T$ is the global-mean surface warming. How effectively warming reestablishes radiative balance is quantified by the total feedback parameter $\lambda$ (in $\mathrm{W} \mathrm{m}^{-2} \mathrm{~K}^{-1}$ ). For a positive (downward) forcing, warming must induce a negative (upward) radiative response to restore balance, and hence $\lambda<0$. When the system reaches a new steady state, $N=0$ and thus the final amount of warming is determined by both forcing and feedback, $\Delta T=-F / \lambda$. A more positive feedback implies more warming.

The total feedback $\lambda$ equals the sum of contributions from different feedback processes, each of which is assumed to perturb the top-of-atmosphere radiative balance by a given amount per degree warming. The largest such process involves the increase in emitted longwave radiation following Planck's law (a negative feedback). Additional feedbacks result from increased longwave emission to space due to enhanced warming aloft (negative lapse rate feedback); increased greenhouse warming by water vapor (positive water vapor feedback); and decreasing reflection of solar radiation as snow and ice retreat (positive surface albedo feedback). Changes in the physical properties of clouds affect 
both their greenhouse warming and their reflection of solar radiation, giving rise to a cloud feedback (Box 2), positive in most current GCMs.

The multi-model-mean net cloud feedback is positive $\left(0.43 \mathrm{~W} \mathrm{~m}^{-2} \mathrm{~K}^{-1}\right)$, suggesting that on average, clouds cause additional warming. However, models produce a wide range of values, from weakly negative to strongly positive $\left(-0.13\right.$ to $\left.1.24 \mathrm{~W} \mathrm{~m}^{-2} \mathrm{~K}^{-1}\right)$. Despite this considerable inter-model spread, only two models, GISS-E2-H and GISS-E2-R, produce a (weakly) negative global-mean cloud feedback. In the multi-model mean, this positive cloud feedback is entirely attributable to the longwave (LW) effect of clouds $\left(0.42 \mathrm{~W} \mathrm{~m}^{-2} \mathrm{~K}^{-1}\right)$, while the mean shortwave (SW) cloud feedback is essentially zero $\left(0.02 \mathrm{~W} \mathrm{~m}^{-2} \mathrm{~K}^{-1}\right)$.

Of all the climate feedback processes, cloud feedback exhibits the largest amount of inter-model spread, originating primarily from the SW effect ${ }^{3,6,26,32}$. The important contribution of clouds to the spread in total feedback parameter and equilibrium climate sensitivity (ECS) stands out in Fig. 1 . The net cloud feedback is strongly correlated with the total feedback parameter $(r=0.80)$ and ECS $(r=0.73)$.

Box 2: Cloud-radiative effect and cloud feedback

The radiative impact of clouds is measured as the cloud-radiative effect (CRE), the difference between clear-sky and all-sky radiative flux at the top of atmosphere. Clouds reflect solar radiation (negative SW CRE, global-mean effect of $-45 \mathrm{~W} \mathrm{~m}^{-2}$ ) and reduce outgoing terrestrial radiation (positive LW CRE, $27 \mathrm{~W} \mathrm{~m}^{-2}$ ), with an overall cooling effect estimated at $-18 \mathrm{~W} \mathrm{~m}^{-2}$ (numbers from Henderson et al. ${ }^{33}$ ). CRE is proportional to cloud fraction, but is also determined by cloud altitude and optical depth. The magnitude of SW CRE increases with cloud optical depth, and to a much lesser extent with cloud altitude. By contrast, the LW CRE depends primarily on cloud altitude, which determines the difference in emission temperature between clear and cloudy skies, but also increases with optical depth.

As the cloud properties change with warming, so does their radiative effect. The resulting radiative flux response at the top of atmosphere, normalized by the global-mean surface temperature increase, is known as cloud feedback. This is not strictly equal to the change in CRE with warming, because the CRE also responds to changes in clear-sky radiation - for example due to changes in surface albedo or water vapor ${ }^{34}$. The CRE response thus underestimates cloud feedback by about 0.3 $\mathrm{W} \mathrm{m}^{-2}$ on average ${ }^{34,35}$. Cloud feedback is therefore the component of CRE change that is due to changing cloud properties only.

Various methods exist to diagnose cloud feedback from standard GCM output. The values presented in this paper are either based on CRE changes corrected for non-cloud effects ${ }^{30}$, or estimated directly from changes in cloud properties, for those GCMs providing appropriate cloud output ${ }^{31}$. The most accurate procedure involves running the GCM radiation code offline - replacing instantaneous cloud fields from a control climatology with those from a perturbed climatology, while keeping other fields unchanged - to obtain the radiative perturbation due to changes in clouds ${ }^{36,37}$. This method is computationally expensive and technically challenging, however. 
109 The cloud-radiative changes that accompany $\mathrm{CO}_{2}$-induced global warming partly result from a rapid adjustment of clouds to $\mathrm{CO}_{2}$ forcing and land-surface warming ${ }^{38,}{ }^{39}$. Because it is unrelated to the global-mean surface temperature increase, this rapid adjustment is treated as a forcing rather than a feedback in the current feedback analysis framework ${ }^{40}$. An important implication is that clouds cause uncertainty in both forcing and feedback. For a quadrupling of $\mathrm{CO}_{2}$ concentration, the estimated global-mean radiative adjustment due to clouds ranges between 0.3 and $1.1 \mathrm{~W} \mathrm{~m}^{-2}$, depending on the analysis method and GCM set, and has been ascribed mainly to SW effects ${ }^{6,41,42}$. Accounting for this adjustment reduces the net and SW component of the cloud feedback. We refer the reader to Andrews et al. ${ }^{43}$ and Kamae et al..$^{44}$ for a thorough discussion of rapid cloud adjustments in GCMs. Hereafter we focus solely on changes in cloud properties that are mediated by increases in globalmean temperature.

Decomposition by cloud type

For models providing output that simulates measurements taken by satellites, the total cloud feedback can be decomposed into contributions from three relevant cloud properties: cloud altitude, amount, and optical depth (plus a small residual) ${ }^{45}$. The multi-model-mean net cloud feedback can then be understood as the sum of positive contributions from cloud altitude and amount changes, and a negative contribution from optical depth changes (Fig. 2a). The various cloud properties have distinctly different effects on LW and SW radiation. Increasing cloud altitude explains most of the positive LW feedback, with minimal effect on SW. By contrast, cloud amount and optical depth changes have opposing effects on SW and LW radiation, with the SW term dominating. (Note that 11 of the 18 feedback values in Fig. 2 include the positive effect of rapid adjustments, yielding a more positive multi-model mean SW feedback compared with Fig. 1.)

The cloud property decomposition in Fig. 2a can be refined by separately considering low (cloud top pressure $>680 \mathrm{hPa}$ ) and free-tropospheric clouds (cloud top pressure $\leq 680 \mathrm{hPa}$ ), as this more effectively isolates the factors contributing to the net cloud feedback ${ }^{26}$. This vertical decomposition reveals that the multi-model mean LW feedback is entirely due to rising free-tropospheric clouds (Fig. 2b). For such clouds, amount and optical depth changes do not contribute to the net feedback because their SW and LW effects cancel nearly perfectly. Meanwhile, the SW cloud feedback can be ascribed to low cloud amount and optical depth changes (Fig. 2c). Thus, the results in Fig. $2 b, c$ highlight the three main contributions to the net cloud feedback in current GCMs: rising freetropospheric clouds (a positive LW effect), decreasing low cloud amount (a positive SW effect), and increasing low cloud optical depth (a weak negative SW effect), yielding a net positive feedback in the multi-model mean. It is noteworthy that all CMIP5 models agree on the sign of these contributions.

\section{Spatial distribution of cloud feedback}

The contributions to LW and SW cloud feedback are far from being spatially homogeneous, reflecting the distribution of cloud regimes (Fig. 3). Although the net cloud feedback is generally positive, negative values occur over the Southern Ocean poleward of about $50^{\circ} \mathrm{S}$, and to a lesser extent over the Arctic and small parts of the tropical oceans. The most positive values are found in 
subtropical oceans. Weak to moderate subsidence regimes cover most of the tropical oceans, and are associated with shallow marine clouds such as stratocumulus and trade cumulus. In most GCMs such clouds decrease in amount ${ }^{17,46}$, strongly contributing to the positive low cloud amount feedback seen in Fig. 2c. This explains the importance of shallow marine clouds for the overall positive cloud feedback, and their dominant contribution to inter-model spread in net cloud feedback ${ }^{17}$.

(a) Standard decomposition

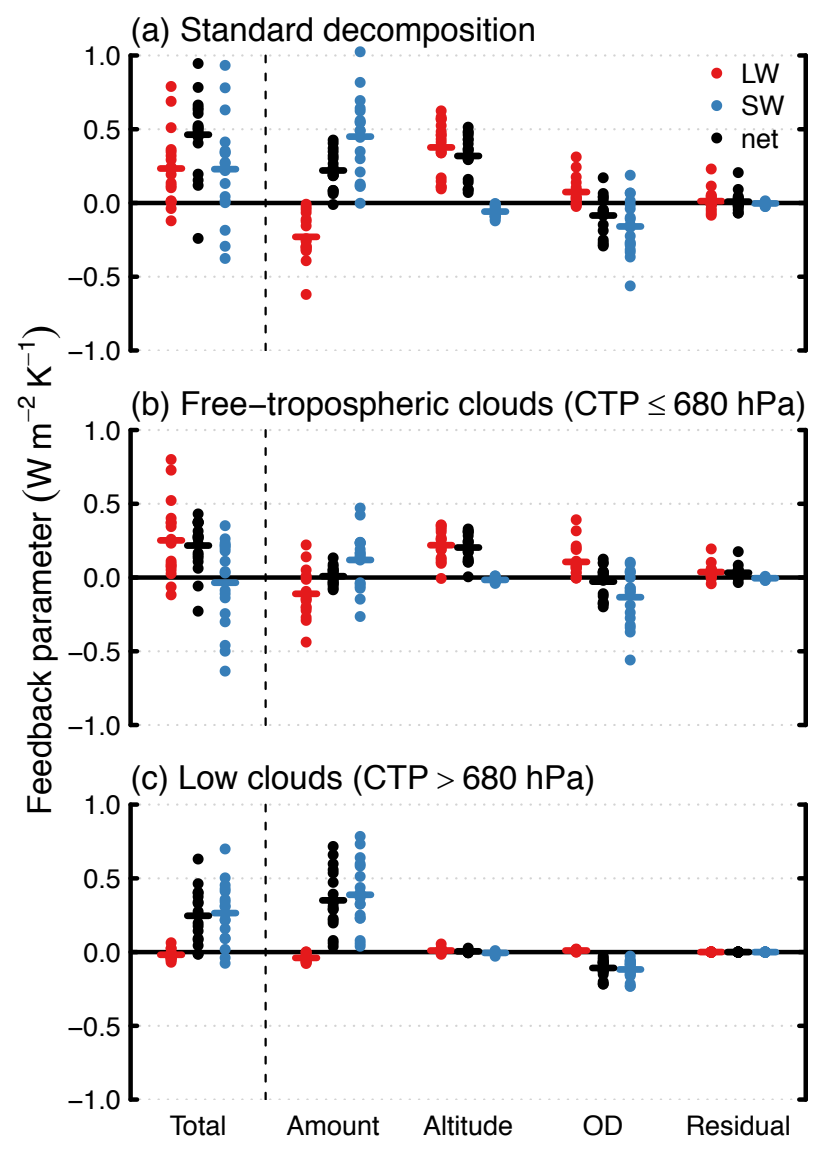

Fig. 2. Global mean LW (red), SW (blue), and net (black) cloud feedbacks decomposed into amount, altitude, optical depth (OD) and residual components for (a) all clouds, (b) free-tropospheric clouds only, and (c) low clouds only, defined by cloud top pressure (CTP). Multi-model mean feedbacks are shown as horizontal lines. Results are based on an analysis of 11 CMIP3 and 7 CMIP5 models ${ }^{26}$; the CMIP3 values do not account for rapid adjustments. Model names and total feedback values are listed in Table S2. Redrawn with permission from Zelinka et al. $^{26}$

Taking a zonal-mean perspective highlights the meridional dependence of cloud property changes and their contributions to cloud feedback (Fig. 4). Free-tropospheric cloud tops robustly rise globally, producing a positive cloud altitude LW feedback at all latitudes that peaks in regions of high climatological free-tropospheric cloud cover (blue curve). The positive cloud amount feedback (orange curve), dominated by the SW effect of low clouds (cf. Fig. 2), also occurs over most of the globe with the exception of the high southern latitudes; by contrast, the effect of optical depth changes is near zero everywhere except at high southern latitudes, where it is strongly negative (green curve). This yields a complex meridional pattern of net cloud feedback (black curve in Fig. 4). 
The patterns of cloud amount and optical depth changes suggest the existence of distinct physical processes in different latitude ranges and climate regimes, as discussed in the next section.

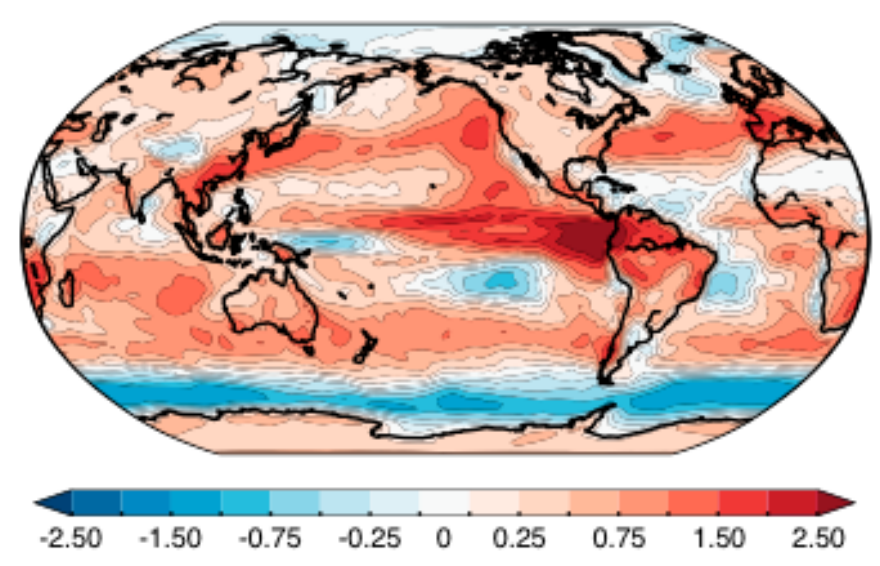

Fig. 3. Spatial distribution of the multi-model mean net cloud feedback (in $\mathrm{W} \mathrm{m}^{-2}$ per $\mathrm{K}$ surface warming) in a set of 11 CMIP3 and 7 CMIP5 models subjected to an abrupt increase in $\mathrm{CO}_{2}$ (Table S2). Redrawn with permission from Zelinka et al. ${ }^{26}$

The results in Fig. 4 allow us to further refine the conclusions drawn from Fig. 2. In the multi-model mean, the cloud feedback in current GCMs mainly results from

- globally rising free-tropospheric clouds,

- decreasing low cloud amount at low to middle latitudes, and

- increasing low cloud optical depth at middle to high latitudes.

\section{Summary}

Cloud feedback is the main contributor to inter-model spread in climate sensitivity, ranging from near zero to strongly positive $\left(-0.13\right.$ to $\left.1.24 \mathrm{~W} \mathrm{~m}^{-2} \mathrm{~K}^{-1}\right)$ in current climate models. It is a combination of three effects present in nearly all GCMs: rising free-tropospheric clouds (a LW heating effect); decreasing low cloud amount in tropics to midlatitudes (a SW heating effect); and increasing low cloud optical depth at high latitudes (a SW cooling effect). Low cloud amount in tropical subsidence regions dominates the inter-model spread in cloud feedback.

\section{INTERPRETING CLOUD PROPERTY CHANGES IN GLOBAL CLIMATE MODELS}

Having diagnosed the radiatively-relevant cloud responses in GCM, we assess our understanding of the physical mechanisms involved in these cloud changes, and discuss their representation in GCMs. We consider in turn each of the three main effects identified in the previous section, and address the following questions: 
- What physical mechanisms are involved in the cloud response? To what extent are these mechanisms supported by theory, high-resolution modeling, and observations?

- How well do GCMs represent these mechanisms, and what parameterizations does this depend on?

- What explains the inter-model spread in cloud responses?

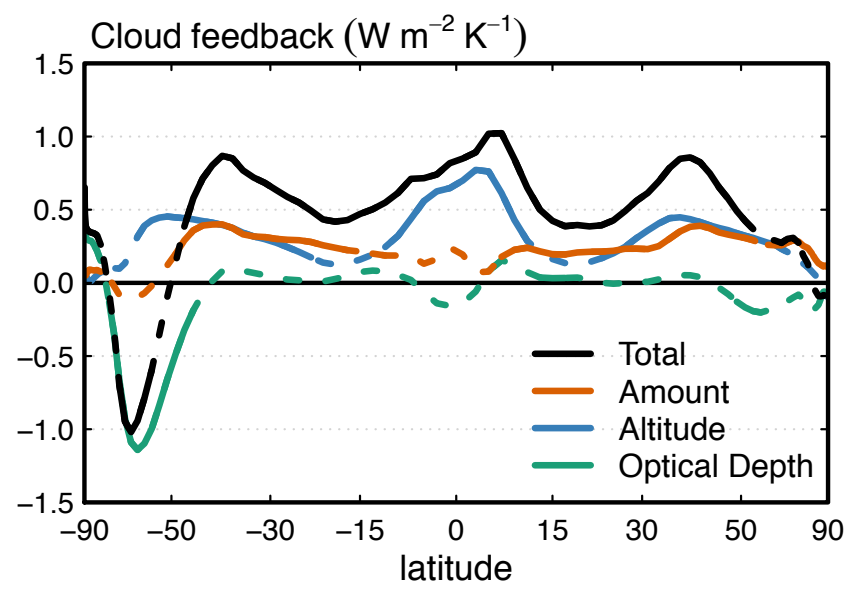

Fig. 4. Zonal-, annual-, and multi-model-mean net cloud feedbacks in a set of 11 CMIP3 and 7 CMIP5 models (Table S2), plotted against the sine of latitude, and partitioned into components due to the change in cloud amount, altitude, and optical depth. Curves are solid where $75 \%$ or more of the models agree on the sign of the feedback, dashed otherwise. Redrawn with permission from Zelinka et al. ${ }^{26}$

\section{Cloud altitude}

\section{Physical mechanisms}

Owing to the decrease of temperature with altitude in the troposphere, higher cloud tops are colder and thus emit less thermal infrared radiation to space. Therefore, an increase in the altitude of cloud tops imparts a heating to the climate system by reducing outgoing LW radiation. Fundamentally, the rise of upper-level cloud tops is firmly grounded in basic theory (the deepening of the well-mixed troposphere as the planet warms), and is supported by cloud-resolving modeling experiments and by observations of both interannual cloud variability and multi-decadal cloud trends. The combination of theoretical and observational evidence, along with the fact that all GCMs simulate rising freetropospheric cloud tops as the planet warms, make the positive cloud altitude feedback one of the most fundamental cloud feedbacks.

The tropical free troposphere is approximately in radiative-convective equilibrium, where latent heating in convective updrafts balances radiative cooling, which is itself primarily due to thermal emission by water vapor ${ }^{47}$. Because radiative cooling by the water vapor rotation and vibration bands falls off rapidly with decreasing water vapor mixing ratio in the tropical upper troposphere ${ }^{48}$, so too must convective mass flux. Hence, mass detrainment from tropical deep convection and its attendant anvil cloud coverage both peak near the altitude where emission from water vapor drops off rapidly with pressure, which we refer to as the altitude of peak radiatively-driven convergence. Because radiative cooling by water vapor is closely tied to water vapor concentration and the latter 
is fundamentally controlled by temperature through the Clausius-Clapeyron equation, the dramatic decrease in water vapor concentration in the upper troposphere occurs primarily due to the decrease of temperature with decreasing pressure. This implies that the level that marks the peak coverage of anvil cloud tops is set by temperature. As isotherms rise with global warming, so too must tropical anvil cloud tops, leading to a positive cloud altitude feedback. This "fixed anvil temperature" (FAT) hypothesis ${ }^{49}$, illustrated schematically in Fig. 5, provides a physical basis for earlier suggestions that fixed cloud top temperature is a more realistic response to warming than fixed cloud altitude ${ }^{50,51}$.

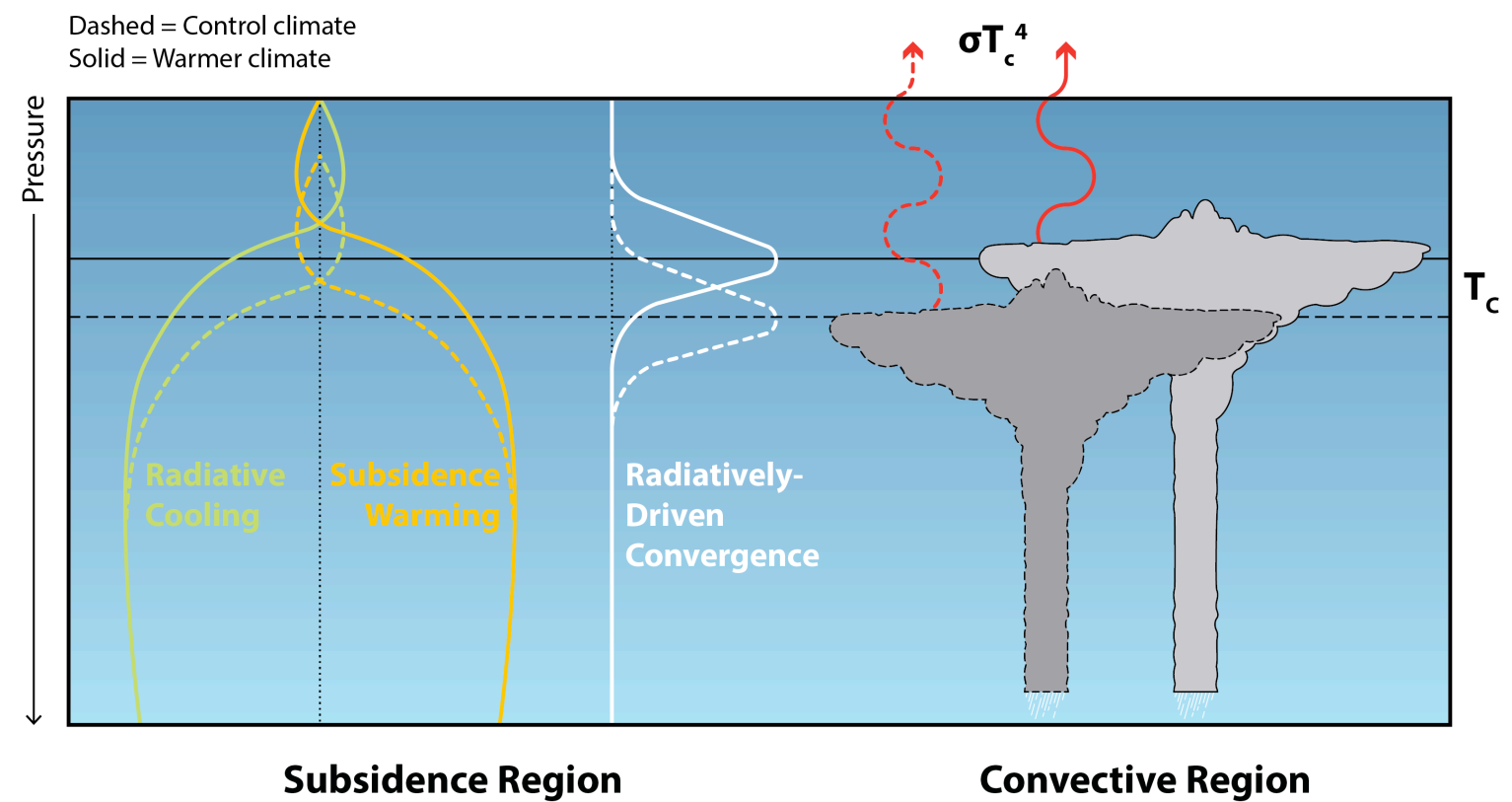

Fig. 5. Schematic of the relationship between clear-sky radiative cooling, subsidence warming, radiativelydriven convergence, and altitude of anvil clouds in the tropics in a control and warm climate, as articulated in the FAT hypothesis. Upon warming, radiative cooling by water vapor increases in the upper troposphere, which must be balanced by enhanced subsidence in clear-sky regions. This implies that the level of peak radiatively-driven convergence and the attendant anvil cloud coverage must shift upward. $T_{C}$ denotes the anvil cloud top temperature isotherm.

In practice, tropical high clouds rise slightly less than the isotherms in response to modeled global warming, leading to a slight warming of their emission temperature - albeit a much weaker warming than occurs at a fixed pressure level (roughly six times smaller) ${ }^{52}$. This is related to an increase in upper tropospheric static stability with warming that was not originally anticipated in the FAT hypothesis. The proportionately higher anvil temperature (PHAT) hypothesis ${ }^{52}$ allows for increases in static stability that cause the level of peak radiatively-driven convergence to shift to slightly warmer temperatures. The upward shift of this level closely tracks the upward shift of anvil clouds under global warming, and captures their slight warming. The aforementioned upper-tropospheric static stability increase has been described as a fundamental consequence of the first law of thermodynamics, which results in static stability having an inverse-pressure dependence ${ }^{21}$, although the radiative effect of ozone has also been shown to play a role ${ }^{53}$. 
Cloud-resolving (horizontal grid spacing $\leq 15 \mathrm{~km}$ ) model simulations of tropical radiative-convective equilibrium support the theoretical expectation that the distribution of free-tropospheric clouds shifts upward with surface warming nearly in lockstep with the isotherms, making their emission temperature increase only slightly ${ }^{53-56}$. This response is also seen in global cloud-resolving models ${ }^{57-}$ 59. This is important for confirming that the response seen in $\mathrm{GCMs}^{21,52}$ and mesoscale models ${ }^{49}$ is not an artifact of parameterized convection. Furthermore, observed interannual relationships between cloud top altitude and surface temperature are also in close agreement with theoretical expectations ${ }^{60-65}$. Recent analyses of satellite cloud retrievals showed that both tropical and extratropical high clouds have shifted upward over the period $1983-2009^{66,67}$.

Although FAT was proposed as a mechanism for tropical cloud altitude feedback, it is possible that radiative cooling by water vapor also controls the vertical extent of extratropical motions, and thereby the strength of extratropical cloud altitude feedback (Thompson et al., submitted manuscript). In any case, the extratropical free tropospheric cloud altitude feedback in GCMs is at least as large as its counterpart in the tropics ${ }^{26}$, despite having received much less attention in the literature.

\section{Box 3: FAT and the cloud altitude feedback}

Cloud tops rising as the surface warms produces a positive feedback: by rising so as to remain at nearly constant temperature, their emission to space does not increase in concert with emission from the clear-sky regions, inhibiting the radiative cooling of the planet under global warming.

The fact that cloud top temperature remains roughly fixed makes the interpretation of the feedback potentially confusing: how can high clouds warm the planet if their emission temperature remains nearly unchanged? It is important to recall that feedbacks due to variable $X$ are defined as the change in radiation due to the temperature-mediated change in $X$ holding all else fixed ${ }^{68}$. In the case where $X$ is cloud top altitude, the feedback quantifies the change in radiation due solely to the change in cloud top altitude, holding the temperature structure of the atmosphere fixed at its unperturbed state. Thus, increased cloud top altitude causes a LW heating effect because - in the radiation calculation - the emission temperature of the cloud top actually decreases by the product of the mean-state lapse rate and the change in the cloud top altitude.

An important point to avoid losing in the details is that as long as the free tropospheric cloud tops rise under global warming, the altitude feedback is positive. The extent to which cloud top temperatures change affects only the magnitude of the feedback, not its sign.

\section{Representation in global climate models and causes of inter-model spread}

Given its solid foundation in well-established physics (radiative-convective equilibrium, ClausiusClapeyron relation), it is unsurprising that all GCMs simulate a nearly isothermal rise in the tops of free tropospheric clouds with warming, in excellent agreement with PHAT. The multi-model mean net free-tropospheric cloud altitude feedback is $0.20 \mathrm{~W} \mathrm{~m}^{-2} \mathrm{~K}^{-1}$, with an inter-model standard deviation of $0.09 \mathrm{~W} \mathrm{~m}^{-2} \mathrm{~K}^{-1}$ (Fig. 1b). Although the spread in this feedback is roughly half as large as that in the low cloud amount feedback, it is still substantial and remains poorly understood. Since 
the altitude feedback is defined as the radiative impact of rising cloud tops while holding everything else fixed (Box 3), the magnitude of this feedback at any given location should be related to (1) the change in free-tropospheric cloud top altitude, (2) the decrease in emitted LW radiation per unit increase of cloud top altitude, and (3) the free-tropospheric cloud fraction. These are discussed in turn below.

Based on the discussion above, one would expect the magnitude of the upward shift of freetropospheric cloud tops (term 1) to be related to the upward shift of the level of radiatively-driven convergence. Both of these are dependent on the magnitude of upper tropospheric warming ${ }^{69,70}$, which varies appreciably across models ${ }^{71,72}$ for reasons that remain unclear.

The decrease in emitted LW radiation per unit increase in cloud top altitude depends on the meanstate temperature and humidity profile of the atmosphere, and on cloud LW opacity. To the extent that inter-model differences in atmospheric thermodynamic structure are small, inter-model variance in term 2 would arise primarily from differences in the mean state cloud opacity, which determines whether an upward shift is accompanied by a large decrease in LW flux (for thick clouds) or a small decrease in LW flux (for thin clouds). Overall, the dependence of LW fluxes on cloud optical thickness is small, however, because clouds of intermediate to high optical depth are completely opaque to infrared radiation. Therefore, we do not expect cloud optical depth biases to dominate the spread in cloud altitude feedback.

Finally, the mean-state free-tropospheric cloud fraction (term 3 ) is likely to exhibit substantial intermodel spread. A four-fold difference in the simulated high (cloud top pressure $\leq 440 \mathrm{hPa}$ ) cloud fraction was found among an earlier generation of models ${ }^{73}$, though this spread has decreased in CMIP5 models ${ }^{12}$. Furthermore, climate models systematically underestimate the relative frequency of occurrence of tropical anvil and extratropical cirrus regimes ${ }^{74,75}$. Taken alone, such biases would lead to models systematically underestimating the cloud altitude feedback.

\section{Low cloud amount}

\section{Physical mechanisms}

The low cloud amount feedback in GCMs is dominated by the response of tropical, warm, liquid clouds located below about $3 \mathrm{~km}$ to surface warming. Several types of clouds fulfill the definition of "low", differing in their radiative effects and in the physical mechanisms underlying their formation, maintenance and response to climate change. So far, most insights into low cloud feedback mechanisms have been gained from high-resolution models - particularly large-eddy simulations (LES) that can explicitly represent the turbulent and convective processes critical for boundary-layer clouds on scales smaller than one kilometer $^{76}$. The low cloud amount feedback in GCMs is determined by the response of the most prevalent boundary-layer cloud types at low latitudes: stratus, stratocumulus, and cumulus clouds.

Although they cover a relatively small fraction of Earth, stratus and stratocumulus (StCu) have a large SW CRE, so that even small changes in their coverage may have significant regional and global impacts. StCu cloud coverage is strongly controlled by atmospheric stability and surface fluxes ${ }^{77}$ : observations suggest a strong relationship between inversion strength at the top of the planetary boundary layer $(\mathrm{PBL})$ and cloud amount ${ }^{78,79}$. A stronger inversion results in weaker mixing with the 
dry free troposphere, shallowing the PBL and increasing cloudiness. Since inversion strength will increase with global warming owing to the stabilization of the free-tropospheric temperature profile $^{80}$, one might expect low cloud amount to increase, implying a negative feedback ${ }^{81}$.

However, LES experiments suggest that StCu clouds are sensitive to other factors than inversion strength, as summarized by Bretherton ${ }^{15}$. Over subsiding regions, (1) increasing atmospheric emissivity owing to water vapor feedback will cause more downward LW radiation, decreasing cloud-top entrainment and thinning the cloud layer (less cloud and hence a positive radiative feedback); (2) the slowdown of the general circulation will weaken subsidence, raising cloud tops and thickening the cloud layer (a negative dynamical feedback); (3) a larger vertical gradient of specific humidity will dry the PBL more efficiently, reducing cloudiness (a positive thermodynamic feedback). Evidence for these physical mechanisms is usually also found in GCMs ${ }^{82-84}$ or when analyzing observed natural variability ${ }^{85-87}$. The real-world StCu feedback will most likely result from the relative importance of these antagonistic processes. LES models forced with an idealized climate change suggest a reduction of StCu clouds with warming ${ }^{76}$.

Shallow cumuli ( $\mathrm{ShCu}$ ) usually denote clouds with tops around 2-3 km localized over weak subsidence regions and higher surface temperature. Despite their more modest SW CRE, ShCu are of major importance to global-mean cloud feedback in GCMs because of their widespread presence across the tropics ${ }^{17}$. Yet mechanisms of ShCu feedback in LES are less robust than for StCu. Usually, LES reduce clouds with warming, with large sensitivity to precipitation (mostly related to microphysical assumptions). This reduction has been explained by a stronger penetrative entrainment that deepens and dries the PBL more efficiently ${ }^{13}{ }^{88}$ (closely related to the thermodynamic feedback seen for StCu), although the strength of this positive feedback may depend on the choice of prescribed or interactive sea surface temperatures (SSTs) ${ }^{89,} 90$ and microphysics parameterization ${ }^{14}$. Other feedbacks seen for StCu may act on ShCu but with different relative importance ${ }^{14}$. Although LES results suggest a positive ShCu feedback ${ }^{14}$, a global model that explicitly resolves the crudest form of convection shows the opposite response $e^{91}$. Hence further work with a hierarchy of model configurations (LES, global cloud-resolving model, GCMs) combined with observational analyses will be needed to validate the ShCu feedback.

Recent observational studies of the low cloud response to changes in meteorological conditions broadly support the StCu and ShCu feedback mechanisms identified in LES experiments ${ }^{84,87,92}$. These studies show that low clouds in both models and observations are mostly sensitive to changes in SST and inversion strength. Although these two effects would tend to cancel each other, observations and GCM simulations constrained by observations suggest that SST-mediated low cloud reduction with warming dominates, increasing the likelihood of a positive low cloud feedback and high climate sensitivity ${ }^{87,93-95}$. Nevertheless, recent ground-based observations of co-variations of ShCu with meteorological conditions suggest that a majority of GCMs are unlikely to represent the temporal dynamics of the cloudy boundary-layer ${ }^{96,}{ }^{97}$. This may reduce our confidence in GCM-based constraints of ShCu feedback with warming.

\section{Representation in global climate models and sources of inter-model spread}

Cloud dynamics depend heavily on small-scale processes such as local turbulent eddies, non-local convective plumes, microphysics, and radiation. Since the typical horizontal grid size of GCMs is around $50 \mathrm{~km}$, such processes are not explicitly simulated and need to be parameterized as a 
function of the large-scale environment. GCMs usually represent cloud-related processes through distinct parameterizations, with separate assumptions for subgrid variability, despite a goal for unification $^{98,99}$. Physical assumptions used in PBL parameterizations often relate cloud formation to buoyancy production, stability, and wind shear. Low cloud amount feedbacks are constrained by how these cloud processes are represented in GCMs and how they respond to climate change perturbations. Since parameterizations are usually crude, it is not evident that the mechanisms of low cloud amount feedback in GCMs are realistic.

All CMIP5 models simulate a positive low cloud amount feedback, but with considerable spread (Fig 2c); this feedback is by far the largest contributor to inter-model variance in net cloud feedback ${ }^{5,17}$, ${ }^{26}$. Spread in low cloud amount feedback can be traced back to differences in parameterizations used in atmospheric GCMs ${ }^{92,100-102}$, and changes in these parameterizations within individual GCMs also have clear impacts on the intensity (and sign) of the response ${ }^{102-104}$. Identifying the low cloud amount feedback mechanisms in GCMs is a difficult task, however, because the low cloud response is sensitive to the competing effects of a variety of unresolved processes. Considering that these processes are parameterized in diverse and complex ways, it appears unlikely that a single mechanism can account for the spread of low cloud amount feedback seen in GCMs.

It has been proposed that convective processes play a key role in driving inter-model spread in low cloud amount feedback ${ }^{105-110}$. As the climate warms, convective moisture fluxes strengthen due to the robust increase of the vertical gradient of specific humidity controlled by the Clausius-Clapeyron relationship ${ }^{82}$. Increasing convective moisture fluxes between the PBL and the free troposphere lead to a relatively drier PBL with decreased cloud amount, suggesting a positive feedback, but the degree to which convective moisture mixing increases seems to strongly depend on model-specific parameterizations $^{109}$. GCMs with stronger present-day convective mixing (and therefore more positive low cloud amount feedback) have been argued to compare better with observations ${ }^{109}$, implying that convective overturning strength could provide an observational constraint on GCM behavior. However, running GCMs with convection schemes switched off does not narrow the spread of cloud feedback ${ }^{111}$, suggesting that non-convective processes may play an important role too $^{92,104}$.

We believe that inter-model spread in low cloud amount feedback does not depend on the representation of convection (deep and shallow) alone, but rather on the interplay between various parameterized processes - particularly convection and turbulence. It has been argued that the relative importance of parameterized convective drying and turbulent moistening of the $\mathrm{PBL}$ accounts for a large fraction of the inter-model differences in both the mean state, and global warming response of low clouds ${ }^{46}$. In GCMs that attribute a large weight to convective drying in the present-day climate, the strengthening of moisture transport with warming causes enhanced PBL ventilation, efficiently reducing low cloud amount ${ }^{109}$. Conversely if convective drying is less active, turbulence moistening induces low cloud shallowing rather than a change in cloud amount ${ }^{46,110}$. In some models, additional parameterization-dependent mechanisms may contribute to the low cloud feedback, such as cloud amount increases by enhancement of surface turbulence ${ }^{83,112}$ or by changes in cloud lifetime ${ }^{113}$. 
416 The primary control on cloud optical depth is the vertically-integrated liquid water content, termed 417 liquid water path (LWP). If other microphysical parameters are held constant, cloud optical depth 418 scales with LWP within the cloud ${ }^{114}$. Cloud optical depth is also affected by cloud particle size and 419 cloud ice content, but the ice effect is smaller since ice crystals are typically several times larger than 420 liquid droplets, and therefore less efficient at scattering sunlight per unit mass ${ }^{115}$. Consistent with 421 this, the cloud optical depth change maps well onto the LWP response in global warming 422 experiments, both quantities increasing at middle to high latitudes in nearly all GCMs ${ }^{18,19,45,116,117}$. 423 Understanding the negative cloud optical depth feedback therefore requires explaining why LWP 424 increases with warming, and why it does so mostly at high latitudes.

Two plausible mechanisms may contribute to LWP increases with warming, and both predict a preferential increase at higher latitudes and lower temperatures. The first mechanism is based upon the assumption that the liquid water content within a cloud is determined by the amount of condensation in saturated rising parcels that follow a moist adiabat $\Gamma_{\mathrm{m}}$, from the cloud base to the cloud top ${ }^{118-120}$. This is often referred to as the "adiabatic" cloud water content. Under this assumption, it may be shown that the change in LWP with temperature is a function of the temperature derivative of the moist adiabat slope, $\partial \Gamma_{\mathrm{m}} / \partial \mathrm{T}$. This predicts that the adiabatic cloud water content always increases with temperature, and increases more strongly at lower temperatures in a relative sense ${ }^{118}$.

A second mechanism involves phase changes in mixed-phase clouds. Liquid water is commonly found in clouds at temperatures substantially below freezing, down to about $-38^{\circ} \mathrm{C}$ where homogeneous freezing occurs ${ }^{115,121}$. Clouds between $-38^{\circ} \mathrm{C}$ and $0^{\circ} \mathrm{C}$ containing both liquid water and ice are termed mixed-phase. As the atmosphere warms, the occurrence of liquid water should increase relative to ice; for a fixed total cloud water path, this would lead to an optically thicker cloud owing to the smaller effective radius of droplets ${ }^{19,115,121}$. In addition, a higher fraction of liquid water is expected to decrease the overall precipitation efficiency, yielding an increase in total cloud water and a further optical thickening of the $\operatorname{cloud}^{19,115,119,121}$. Reduced precipitation efficiency may also increase cloud lifetime, and hence cloud amount ${ }^{121,122}$. Because the phase change mechanism can only operate below freezing, its occurrence in low clouds is restricted to middle and high latitudes.

Satellite and in-situ observations of high-latitude clouds support increases in cloud LWP and optical depth with temperature ${ }^{18,19,120}$, and suggest a negative cloud optical depth feedback ${ }^{20}$, although this result is sensitive to the analysis method ${ }^{123}$. The positive LWP sensitivity to temperature is generally restricted to mixed-phase regions and is typically larger than that expected from moist adiabatic increases in water content alone ${ }^{18,19}$. This lends observational support for the importance of phase change processes. While the moist adiabatic mechanism should still contribute to LWP increases with warming, LES modeling of warm boundary-layer clouds (in which phase change processes play no role) suggests that optical depth changes are small relative to the effects of drying and deepening of the boundary layer with warming ${ }^{13}$. 
The low cloud optical depth feedback predicted by GCMs can only be trusted to the extent that the driving mechanisms are understood and correctly represented. We therefore ask, how reliably are these physical mechanisms represented in GCMs? The first mechanism involves the source of cloud water from condensation in saturated updrafts. It results from basic, well-understood thermodynamics that do not directly rely on physical parameterizations, and should be correctly implemented in all models. As such, it constitutes a simple and powerful constraint on the cloud water content response to warming, to the point that some early studies proposed the global cloud feedback might be negative as a result ${ }^{124-126}$. Considering this mechanism in isolation ignores important competing factors that affect the cloud water budget, however, such as the entrainment of dry air into the convective updrafts, phase change processes, or precipitation efficiency. The competition between these various factors may explain why no simple, robust LWP increase with temperature is seen in all regions across the world in GCMs.

The second mechanism is primarily related to the liquid water sink through conversion to ice and precipitation by ice-phase microphysical processes. The representation of cloud microphysics in state-of-the-art GCMs is mainly prognostic, meaning that rates of change between the different phases - vapor, liquid, ice, and precipitation - are computed. Rather than being a direct function of temperature (as in a diagnostic scheme), the relative amounts of liquid and ice thus depend on the efficiencies of the source and sink terms. In GCMs, cloud water production in mixed-phase clouds occurs mainly in liquid form; subsequent glaciation may occur through a variety of microphysical processes, particularly the Wegener-Bergeron-Findeisen ${ }^{127}$ mechanism (see Storelvmo et al. ${ }^{128}$ for a description and a review). Ice-phase microphysics are therefore mainly a sink of cloud liquid water. Upon warming, this sink should become suppressed, resulting in a larger reservoir of cloud liquid water $^{19}$.

In GCMs, the optical depth feedback is likely dominated by microphysical phase change processes. Several lines of evidence support this idea. As in observations, low cloud optical depth increases with warming almost exclusively at high latitudes, and the increase in cloud water content is typically restricted to temperatures below freezing ${ }^{117,129,130}$ - a finding that cannot be satisfactorily explained by the adiabatic water content mechanism. Imposing a temperature increase only in the ice-phase microphysics explains roughly $80 \%$ of the total LWP response to warming in two contemporary GCMs run in aquaplanet configuration ${ }^{19}$. Furthermore, changes in the efficiency of phase conversion processes have dramatic impacts on the cloud water climatology and sensitivity to warming in $\mathrm{GCMs}^{131-133}$.

\section{Causes of inter-model spread}

Although GCMs agree on the sign of the cloud optical depth response in mixed-phase clouds, the magnitude of the change remains highly uncertain. This is in large part because the efficiency of phase change processes varies widely between models, impacting the mean state and the sensitivity to warming ${ }^{116}$.

GCMs separately simulate microphysical processes for cloud water resulting from large-scale (resolved) vertical motions, and convective (unresolved, parameterized) motions. In convection schemes, microphysical phase conversions are crudely represented, usually as simple, model- 
dependent analytic functions of temperature. While the representation of microphysical processes is much more refined in large-scale microphysics schemes, ice-phase processes remain diversely represented due to limitations in our understanding, particularly with regard to ice formation processes ${ }^{134,}{ }^{135}$. In models explicitly representing aerosol-cloud interactions, an additional uncertainty results from poorly constrained ice nuclei concentrations ${ }^{122}$. For mixed-phase clouds, perturbing the parameterizations of phase transitions can significantly affect the ratio of liquid water to ice, the overall cloud water budget, and cloud-radiative properties ${ }^{19},{ }^{133}$. Owing to these uncertainties, the simple constraint that the liquid water fraction must increase with warming is strong but merely qualitative in GCMs.

It is believed that mixed-phase clouds may become glaciated too readily in most GCMs ${ }^{121,} 128$. Satellite retrievals suggest models underestimate the supercooled liquid fraction in cold clouds ${ }^{132,136-}$ 138; this may be because models assume too much spatial overlap between ice and supercooled clouds, overestimating the liquid-to-ice conversion efficiency ${ }^{128}$. An expected consequence is that liquid water and cloud optical depth increase too dramatically with warming in GCMs, since there is too much climatological cloud ice in a fractional sense. Comparisons with observations appear to support that idea ${ }^{18,20}$. Such microphysical biases could have powerful implications for the optical

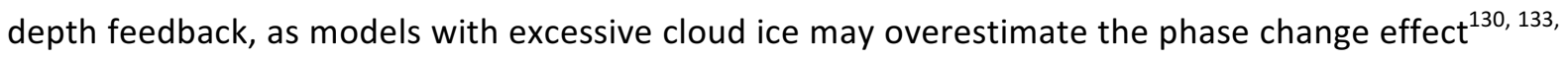
139,140 . In summary, the current understanding is that the negative cloud optical depth feedback is likely too strong in most GCMs. Further work with observational data is needed to constrain GCMs and confirm the existence of a negative optical depth feedback in the real world.

\section{Other possible cloud feedback mechanisms: tropical and extratropical dynamics}

While the mechanisms discussed above are mainly linked to the climate system's thermodynamic response to $\mathrm{CO}_{2}$ forcing, dynamical changes could have equally important implications for clouds and radiation. This poses a particular challenge: not only are the cloud responses to a given dynamical forcing uncertain ${ }^{141}$, but the future dynamical response is also much more poorly constrained than the thermodynamic one ${ }^{142}$. Below we discuss two possible effects of changes in atmospheric circulation, one involving the degree of aggregation of tropical convection, and another based on extratropical circulation shifts with warming. We assess the relevance of these proposed feedback processes in GCMs and in the real world.

\section{Convective aggregation and the "iris effect"}

Tropical convective clouds both reduce outgoing LW radiation and reflect solar radiation. These effects tend to offset each other, and over the broad expanse of warm waters in the western Pacific and Indian Ocean areas these two effects very nearly cancel, so that net cloud radiative effect is about zero ${ }^{143-145}$. The net neutrality of tropical cloud radiative effects results from a cancellation between positive effects of thin anvil clouds and negative effects of the thicker rainy areas of the cloud $^{146}$. That convective clouds tend to rise in a warmed climate has been discussed above, but it is also possible that the optical depth or area coverage of convective clouds could change in a warmed climate. For high clouds with no net effect on the radiation balance, a change in area coverage without change in the average radiative properties of the clouds would have little effect on the energy balance (unless the high clouds are masking bright low clouds). Because the individual LW and SW effects of tropical convective clouds are large, a small change in the balance of these effects could also provide a large feedback. 
So far more attention has been directed at oceanic boundary layer clouds, whose net CRE is large, since their substantial SW effect is not balanced by their relatively small LW effect. But since the SW effect of tropical convective clouds is as large as that of boundary-layer clouds in stratocumulus regimes, a substantial feedback could occur if the relative area coverage of thin anvils versus rainy cores with higher albedos changes in a way to disrupt the net radiative neutrality of convective clouds. Relatively little has been done on this problem, since global climate models do not resolve or explicitly parameterize the physics of convective complexes and their associated meso- and microscale processes.

It has been proposed that tropical anvil cloud area should decrease in a warmed climate, possibly causing a negative LW feedback, but the theoretical and observational basis for this hypothesis remains controversial ${ }^{147-151}$. The response of tropical high cloud amount to warming in GCMs is very sensitive to the particular parameterizations of convection and cloud microphysics that are employed $^{107,152}$, as might be expected.

One basic physical argument for changing the area of tropical high clouds with warming involves simple energy balance and the dependence of saturation vapor pressure on temperature ${ }^{35}$. The basic energy balance of the atmosphere is radiative cooling balanced by latent heating. Convection must bring enough latent heat upward to balance radiative losses. Radiative losses increase rather slowly with surface temperature $(\sim 1.5 \%$ per $\mathrm{K})$, whereas the latent energy in the atmosphere vapor pressure times convective mass flux, it follows that convective mass flux must decrease as the planet warms ${ }^{35}$. If the cloud area decreases with the mass flux, then the high cloud area should decrease with warming. Some support for this mechanism is found in global cloud-resolving model experiments ${ }^{57}$.

Another mechanism is the tendency of tropical deep convection to aggregate in part of the domain, leaving another part of the domain with little high cloud and low relative humidity. This is observed to happen in radiative-convective equilibrium models in which the mesoscale dynamics of convective clouds is resolved ${ }^{154-156}$, although the relevance of this mechanism to realistic models and the real world remains unclear. The presence of convection moistens the free troposphere, and the radiative and microphysical effects of this encourage convection to form where it has already influenced the environment. Away from the convection, the air is dry and radiative cooling supports subsidence that suppresses convection. It has been argued that since self-aggregation occurs at high temperatures, global warming may lead to a greater concentration of convection that may reduce the convective area and lead to a cloud feedback ${ }^{21}$. Since tropical convection is also organized by the large-scale circulations of the tropics, and the physics of tropical anvil clouds are not wellrepresented in global models, these ideas remain a topic of active research. Basic thermodynamics make the static stability a function of pressure, which may affect the fractional coverage of high clouds in the tropics ${ }^{21,52}$.

\section{Shifts in midlatitude circulation with global warming}

Atmospheric circulation is a key control on cloud structure and radiative properties ${ }^{157}$. Because current GCMs predict systematic shifts of subtropical and extratropical circulation toward higher latitudes as the planet warms ${ }^{158}$, it has been suggested that midlatitude clouds will shift toward regions of reduced insolation, causing an overall positive SW feedback ${ }^{3,159}$. 
579 Although this poleward shift of storm-track clouds counts among the robust positive cloud feedback mechanisms identified in the fifth IPCC assessment report (Fig. 7.11 in Boucher et al. ${ }^{3}$ ), the picture is much less clear in analyses of cloud-radiative responses to storm track shifts in GCM experiments. While some GCMs produce a clear cloud-radiative SW dipole in response to storm track shifts ${ }^{160}$, others simulate no clear zonal- or global-mean SW response ${ }^{24,161-163}$. In the context of observed variability, the GCMs with no significant cloud-radiative response to a storm-track shift are clearly more consistent with observations ${ }^{22,24}$. The lack of an observed SW cloud feedback to storm track shifts results from free-tropospheric and boundary-layer clouds responding to storm track variability in opposite ways. As the storms shift poleward, enhanced subsidence in the midlatitudes causes free-tropospheric drying and cloud amount decreases, resulting in the expected shift of freetropospheric cloudiness. Meanwhile, however, lower-tropospheric stability increases, favoring enhanced boundary-layer cloudiness and maintaining the SW CRE nearly unchanged ${ }^{24}$. The ability of GCMs to reproduce this behavior has been linked to their shallow convection schemes ${ }^{163}$ and to their representation of the effect of stability on boundary-layer cloud ${ }^{24}$. If unforced variability provides a good analog for the cloud response to forced dynamical changes - thought to be approximately true in $\mathrm{GCMs}^{163}$ - then the above results suggest little SW radiative impact from future jet and storm track shifts.

Since LW radiation is much more sensitive to the response of free-tropospheric clouds than to low cloud changes, storm-track shifts do cause coherent LW cloud-radiative anomalies ${ }^{23}$. These anomalies are small in the context of global warming-driven cloud feedback, however ${ }^{23}$, so that future shifts in midlatitude circulation appear unlikely to be a major contribution to global-mean LW cloud feedback. Given the strong seasonality of LW and SW cloud-radiative anomalies, it remains possible that extratropical circulation shifts have non-negligible radiative impacts on seasonal time scales $^{164,165}$. It is also possible that clouds and radiation respond more strongly to other aspects of atmospheric circulation than the midlatitude jets and storm tracks; it has been recently proposed that midlatitude cloud changes are more strongly tied to Hadley cell shifts than to the jet ${ }^{165}$. Further observational and modeling work is needed to confirm these relationships and assess their relevance to cloud feedback.

\section{CONCLUDING REMARKS}

Possible pathways to an improved representation of cloud feedback in GCMs

Recent progress on the problem of cloud feedback has enabled unprecedented advances in processlevel understanding of cloud responses to $\mathrm{CO}_{2}$ forcing. The main cloud property changes responsible for radiative feedback in GCMs - rising high clouds, decreasing tropical low cloud amount, increasing low cloud optical depth - are supported to varying degree by theoretical reasoning, high-resolution modeling, and observations.

Much of the recent gains in understanding of radiatively-important tropical low cloud changes have been accomplished through the use of limited-area, high-resolution LES models, able to explicitly represent the critical boundary layer processes unresolved by GCMs. Because limited-area models must be forced with prescribed climate change conditions, however, such models are unable to represent the important feedbacks of clouds onto the large-scale climate. To fully understand how 
cloud feedback affects climate sensitivity, atmospheric and oceanic circulation, and regional climate, we must rely on global models.

Accurately representing clouds and their radiative effects in global models remains a formidable challenge, however, and GCM spread in cloud feedback has not decreased substantially in recent decades. Uncertainties in the global warming response of clouds are linked to the difficulty in representing the complex interactions among the various physical processes at play - radiation, microphysics, convective and turbulent fluxes, dynamics - through traditional GCM parameterizations. Owing to sometimes unphysical interactions between individual parameterizations, cloud feedback mechanisms may differ between $\mathrm{GCMs}^{46}{ }^{110}$, and these mechanisms may also be distinct from those acting in the real world.

One approach to circumvent the shortcomings of traditional GCM parameterizations involves embedding a cloud-resolving model in each GCM grid box over part of the horizontal domain ${ }^{166-168}$. Such "superparameterized" GCMs can thus explicitly simulate some of the convective motions and subgrid variability that traditional parameterizations fail to represent accurately, while remaining computationally affordable relative to global cloud-resolving models. However, superparameterized GCMs remain unable to resolve the boundary-layer processes controlling radiatively-important low clouds - and similarly to global cloud resolving models, they report disappointingly large spread in their cloud feedback estimates ${ }^{15}$.

A recent further development, made possible by steady increases in computing power, involves the use of LES rather than cloud-resolving models as a substitute for GCM parameterizations ${ }^{16,169}$. First results suggest encouraging improvements in the representation of boundary-layer clouds (C. Bretherton, pers. comm.). Superparameterization with LES combines aspects of the model hierarchy into a single model, making it possible to represent both the small-scale processes and their impact on the large scales. Analyses of superparameterized model experiments could also be used to design more realistic parameterizations to improve boundary-layer characteristics, cloud variability, and thus cloud feedback in traditional GCMs. An important caveat, however, is that current LES superparameterizations are relatively coarse and may not represent processes such as entrainment well, so that further increases in computing power may be necessary to fully exploit the possibilities of LES superparameterization.

Irrespective of future increases in spatial resolution, GCMs will continue requiring parameterization of the important microphysical processes of liquid droplet and ice crystal formation. As discussed in this review, microphysical processes constitute a major source of uncertainty in future cloud responses, particularly with regard to mixed-phase cloud radiative properties ${ }^{19}$ and precipitation efficiency in convective clouds ${ }^{107}$. The treatment of cloud-aerosol interactions also remains deficient in current parameterizations ${ }^{170}$. Improving the parameterization of microphysical processes must therefore remain a priority for future work; this will involve a combined use of laboratory experiments ${ }^{171}$, and satellite and in-situ observations of cloud phase ${ }^{119,138}$.

Although the main focus of this paper has been on the representation of clouds in GCMs, observational analyses will remain crucial to advance our understanding of cloud feedback, in conjunction with process-resolving modeling and global modeling. On the one hand, reliable observations of clouds and their environment at both local and global scales are indispensable to test and improve process-resolving models and GCM parameterizations. On the other hand, models 
can provide process-based understanding of the relationship between clouds and the large-scale environment, which can be exploited to identify observational constraints on cloud feedback.

\section{Current limits of understanding}

We conclude this review by highlighting two problems which we regard as key limitations in our understanding of how cloud feedback impacts the climate system's response to external forcing. The first problem relates to the relevance of cloud feedback to future atmospheric circulation changes, which control climate change impacts at regional scales ${ }^{142}$. The circulation response is driven by changes in diabatic heating, to which the radiative effects of clouds are an important contribution. Hence cloud feedbacks must affect the dynamical response to warming, but the dynamical implications of cloud feedback are just beginning to be quantified and understood. Recent work has shown that cloud feedbacks have large impacts on the forced dynamical response to warming and particularly the shift of the jets and storm tracks ${ }^{22,161,172,173}$. Thus the cloud response to warming appears as one of the key uncertainties for future circulation changes. Substantial research efforts are currently underway to improve our understanding of cloud-circulation interactions at various scales and their implications for climate sensitivity, a problem identified as one of the current "grand challenges" of climate science ${ }^{173-175}$.

Our second point concerns the problem of time dependence of cloud feedback. The traditional feedback analysis framework is based on the simplifying assumption that feedback processes scale with global-mean surface temperature, independent of the spatial pattern of warming. However, recent research shows that the global feedback parameter does depend upon the pattern of surface warming, which itself changes over time in $\mathrm{CO}_{2}$-forced experiments ${ }^{7,176-178}$. In particular, most CMIP5 models subjected to an abrupt quadrupling of $\mathrm{CO}_{2}$ concentrations indicate that the SW cloud feedback parameter increases after about two decades, and this is a direct consequence of changes in the SST warming pattern ${ }^{179}$. Since future patterns of SST increase are uncertain in GCMs, and may differ from those observed in the historical record, this introduces an additional uncertainty in the magnitude of global-mean cloud feedback and our ability to constrain it using observations ${ }^{180,181}$. Therefore, further work is necessary to understand what determines the spatial patterns of SST increase, and how these patterns influence cloud properties at regional and global scales.

\section{ACKNOWLEDGMENTS}

The authors thank two anonymous reviewers for their very insightful and constructive comments. We are also grateful to Chris Bretherton, Jonathan Gregory, Tapio Schneider, Bjorn Stevens, and Mark Webb for helpful discussions. PC acknowledges support from the ERC Advanced Grant "ACRCC". DLH was supported by the Regional and Global Climate Modeling Program of the Office of Science of the U.S. Department of Energy (DE-SC0012580). The effort of MDZ was supported by the Regional and Global Climate Modeling Program of the Office of Science of the U.S. Department of Energy (DOE) and by the NASA New Investigator Program (NNH14AX83I) and was performed under the auspices of the DOE by Lawrence Livermore National Laboratory under contract DE-AC5207NA27344. IM Release LLNL-JRNL-707398. We also acknowledge the World Climate Research Program's Working Group on Coupled Modeling, which is responsible for CMIP, and we thank the climate modeling groups (listed in the Supporting Information) for producing and making available 
their model output. For CMIP the U.S. Department of Energy's Program for Climate Model Diagnosis and Intercomparison provides coordinating support and led development of software infrastructure in partnership with the Global Organization for Earth System Science Portals.

\section{FURTHER READING}

A very useful review of cloud feedbacks in high-resolution models: Bretherton CS. Insights into lowlatitude cloud feedbacks from high-resolution models. Philosophical transactions. Series A, Mathematical, physical, and engineering sciences 2015, 373:3354-3360

A discussion of cloud phase changes in high-latitude clouds: Storelvmo T, Tan I, Korolev AV. Cloud Phase Changes Induced by $\mathrm{CO} 2$ Warming - a Powerful yet Poorly Constrained Cloud-Climate Feedback. Current Climate Change Reports 2015, 1:288-296

A review on interactions between dynamics and clouds in the extratropics, including a discussion of the roles of storm-track shifts in future cloud feedbacks: Ceppi P, Hartmann DL. Connections Between Clouds, Radiation, and Midlatitude Dynamics: a Review. Current Climate Change Reports 2015, 1:94-102

\section{REFERENCES}

1. Manabe S, Wetherald RT. Thermal Equilibrium of the Atmosphere with a Given Distribution of Relative Humidity. Journal of the Atmospheric Sciences 1967, 24:241-259.

2. Schneider SH. Cloudiness as a Global Climatic Feedback Mechanism: The Effects on the Radiation Balance and Surface Temperature of Variations in Cloudiness. Journal of the Atmospheric Sciences 1972, 29:1413-1422.

3. Boucher $\mathrm{O}$, Randall D, Artaxo P, Bretherton C, Feingold G, Forster P, Kerminen V-M, Kondo $\mathrm{Y}$, Liao H, Lohmann U, et al. Clouds and Aerosols. In: Stocker TF, Qin D, G.-K P, Tignor M, Allen SK, Boschung J, Nauels A, Xia Y, Bex V, Midgley PM, eds. Climate Change 2013: The Physical Science Basis. Contribution of Working Group I to the Fifth Assessment Report of the Intergovernmental Panel on Climate Change. Cambridge, United Kingdom and New York, NY, USA: Cambridge University Press; 2013, 571-657.

4. Taylor KE, Stouffer RJ, MeehI GA. An Overview of CMIP5 and the Experiment Design. Bulletin of the American Meteorological Society 2012, 93:485-498.

5. Caldwell PM, Zelinka MD, Taylor KE, Marvel K. Quantifying the Sources of Intermodel Spread in Equilibrium Climate Sensitivity. Journal of Climate 2016, 29:513-524.

6. Vial J, Dufresne J-L, Bony S. On the interpretation of inter-model spread in CMIP5 climate sensitivity estimates. Climate Dynamics 2013, 41:3339-3362.

7. Stevens B, Sherwood SC, Bony S, Webb MJ. Prospects for narrowing bounds on Earth's equilibrium climate sensitivity. Earth's Future 2016, 4:512-522.

8. Arakawa A. Modelling clouds and cloud processes for use in climate models. In: GARP Publication Series No. 16: WMO; 1975, 183-197.

9. Charney JG, Arakawa A, Baker DJ, Bolin B, Dickinson RE, Goody RM, Leith CE, Stommel HM, Wunsch Cl. Carbon Dioxide and Climate: A Scientific Assessment. Report of an Ad Hoc Study Group on Carbon Dioxide and Climate 1979.

10. Mitchell JFB. The "Greenhouse" effect and climate change. Reviews of Geophysics 1989, 27:115-115. 
11. Cess RD, Potter GL, Blanchet JP, Boer GJ, Del Genio AD, Déqué M, Dymnikov V, Galin V, Gates WL, Ghan SJ, et al. Intercomparison and interpretation of climate feedback processes in 19 atmospheric general circulation models. Journal of Geophysical Research 1990, 95:16601.

12. Klein SA, Zhang Y, Zelinka MD, Pincus R, Boyle J, Gleckler PJ. Are climate model simulations of clouds improving? An evaluation using the ISCCP simulator. Journal of Geophysical Research-Atmospheres 2013, 118:1329-1342.

13. Rieck M, Nuijens L, Stevens B. Marine Boundary Layer Cloud Feedbacks in a Constant Relative Humidity Atmosphere. Journal of the Atmospheric Sciences 2012, 69:2538-2550.

14. Bretherton CS, Blossey PN, Jones CR. Mechanisms of marine low cloud sensitivity to idealized climate perturbations: A single-LES exploration extending the CGILS cases. Journal of Advances in Modeling Earth Systems 2013, 5:316-337.

15. Bretherton CS. Insights into low-latitude cloud feedbacks from high-resolution models. Philosophical transactions. Series A, Mathematical, physical, and engineering sciences 2015, 373:3354-3360.

16. Schneider T, Teixeira J, Bretherton CS, Brient F, Pressel KG, Schär C, Siebesma AP. Climate goals and computing the future of clouds. Nature Climate Change 2017, 7:3-5.

17. Bony S, Dufresne J-L. Marine boundary layer clouds at the heart of tropical cloud feedback uncertainties in climate models. Geophysical Research Letters 2005, 32:L20806.

18. Gordon ND, Klein SA. Low-cloud optical depth feedback in climate models. Journal of Geophysical Research: Atmospheres 2014, 119:6052-6065.

19. Ceppi P, Hartmann DL, Webb MJ. Mechanisms of the negative shortwave cloud feedback in high latitudes. Journal of Climate 2016, 29:139-157.

20. Ceppi P, McCoy DT, Hartmann DL. Observational evidence for a negative shortwave cloud feedback in middle to high latitudes. Geophysical Research Letters 2016, 43:1331-1339.

21. Bony S, Stevens B, Coppin D, Becker T, Reed KA, Voigt A, Medeiros B. Thermodynamic control of anvil cloud amount. Proceedings of the National Academy of Sciences 2016.

22. Grise KM, Polvani LM. Southern Hemisphere Cloud-Dynamics Biases in CMIP5 Models and Their Implications for Climate Projections. Journal of Climate 2014, 27:6074-6092.

23. Ceppi P, Hartmann DL. Connections Between Clouds, Radiation, and Midlatitude Dynamics: a Review. Current Climate Change Reports 2015, 1:94-102.

24. Grise KM, Medeiros B. Understanding the varied influence of mid-latitude jet position on clouds and cloud-radiative effects in observations and global climate models. Journal of Climate 2016:JCLI-D-16-0295.0291.

25. Klein SA, Hall A. Emergent Constraints for Cloud Feedbacks. Current Climate Change Reports 2015, 1:276-287.

26. Zelinka MD, Zhou C, Klein SA. Insights from a Refined Decomposition of Cloud Feedbacks. Geophysical Research Letters 2016, 43:9259-9269.

27. Andrews T, Gregory JM, Webb MJ, Taylor KE. Forcing, feedbacks and climate sensitivity in CMIP5 coupled atmosphere-ocean climate models. Geophysical Research Letters 2012, 39:n/a-n/a.

28. Forster PM, Andrews T, Good P, Gregory JM, Jackson LS, Zelinka M. Evaluating adjusted forcing and model spread for historical and future scenarios in the CMIP5 generation of climate models. Journal of Geophysical Research: Atmospheres 2013, 118:1139-1150.

29. Flato G, Marotzke J, Abiodun B, Braconnot P, Chou SC, Collins W, Cox P, Driouech F, Emori S, Eyring V, et al. Evaluation of Climate Models. Climate Change 2013: The Physical Science Basis. Contribution of Working Group I to the Fifth Assessment Report of the Intergovernmental Panel on Climate Change 2013, Pages 741-866.

30. Soden BJ, Held IM, Colman R, Shell KM, KiehI JT, Shields CA. Quantifying Climate Feedbacks Using Radiative Kernels. Journal of Climate 2008, 21:3504-3520. 
31. Zelinka MD, Klein SA, Hartmann DL. Computing and Partitioning Cloud Feedbacks Using Cloud Property Histograms. Part I: Cloud Radiative Kernels. Journal of Climate 2012, 25:3715-3735.

32. Tomassini L, Geoffroy O, Dufresne J-L, Idelkadi A, Cagnazzo C, Block K, Mauritsen T, Giorgetta $M$, Quaas J. The respective roles of surface temperature driven feedbacks and tropospheric adjustment to CO2 in CMIP5 transient climate simulations. Climate Dynamics 2013, 41:31033126.

33. Henderson DS, L'Ecuyer T, Stephens G, Partain P, Sekiguchi M. A Multisensor Perspective on the Radiative Impacts of Clouds and Aerosols. Journal of Applied Meteorology and Climatology 2013, 52:853-871.

34. Soden BJ, Broccoli AJ, Hemler RS. On the Use of Cloud Forcing to Estimate Cloud Feedback. Journal of Climate 2004, 17:3661-3665.

35. Held IM, Soden BJ. Robust Responses of the Hydrological Cycle to Global Warming. Journal of Climate 2006, 19:5686-5699.

36. Colman R. A comparison of climate feedbacks in general circulation models. Climate Dynamics 2003, 20:865-873.

37. Colman RA, McAvaney BJ. A study of general circulation model climate feedbacks determined from perturbed sea surface temperature experiments. Journal of Geophysical Research 1997, 102:19383.

38. Andrews T, Forster PM. CO2 forcing induces semi-direct effects with consequences for climate feedback interpretations. Geophysical Research Letters 2008, 35:L04802.

39. Gregory J, Webb M. Tropospheric Adjustment Induces a Cloud Component in $\mathrm{CO} 2$ Forcing. Journal of Climate 2008, 21:58-71.

40. Sherwood SC, Bony S, Boucher O, Bretherton C, Forster PM, Gregory JM, Stevens B. Adjustments in the Forcing-Feedback Framework for Understanding Climate Change. Bulletin of the American Meteorological Society 2015, 96:217-228.

41. Chung E-S, Soden BJ. An Assessment of Direct Radiative Forcing, Radiative Adjustments, and Radiative Feedbacks in Coupled Ocean-Atmosphere Models. Journal of Climate 2015, 28:4152-4170.

42. Zelinka MD, Klein SA, Taylor KE, Andrews T, Webb MJ, Gregory JM, Forster PM. Contributions of Different Cloud Types to Feedbacks and Rapid Adjustments in CMIP5. Journal of Climate 2013, 26:5007-5027.

43. Andrews T, Gregory JM, Forster PM, Webb MJ. Cloud Adjustment and its Role in CO2 Radiative Forcing and Climate Sensitivity: A Review. Surveys in Geophysics 2012, 33:619-635.

44. Kamae $Y$, Watanabe M, Ogura T, Yoshimori M, Shiogama H. Rapid Adjustments of Cloud and Hydrological Cycle to Increasing CO2: a Review. Current Climate Change Reports 2015, 1:103113.

45. Zelinka MD, Klein SA, Hartmann DL. Computing and Partitioning Cloud Feedbacks Using Cloud Property Histograms. Part II: Attribution to Changes in Cloud Amount, Altitude, and Optical Depth. Journal of Climate 2012, 25:3736-3754.

46. Brient F, Schneider T, Tan Z, Bony S, Qu X, Hall A. Shallowness of tropical low clouds as a predictor of climate models' response to warming. Climate Dynamics 2016, 47:433-449.

47. Manabe S, Strickler RF. Thermal Equilibrium of the Atmosphere with a Convective Adjustment. Journal of the Atmospheric Sciences 1964, 21:361-385.

48. Clough SA, lacono MJ, Moncet JL. Line-by-line calculations of atmospheric fluxes and cooling rates: Application to water vapor. Journal of Geophysical Research-Atmospheres 1992, 97:15761-15785.

49. Hartmann DL, Larson K. An important constraint on tropical cloud--climate feedback. Geophysical Research Letters 2002, 29:1951. 
50. Cess RD. Radiative transfer due to atmospheric water vapor: Global considerations of the earth's energy balance. Journal of Quantitative Spectroscopy and Radiative Transfer 1974, 14:861-871.

51. Ramanathan V, Coakley JA. Climate modeling through radiative-convective models. Reviews of Geophysics 1978, 16:465-489.

52. Zelinka MD, Hartmann DL. Why is longwave cloud feedback positive? Journal of Geophysical Research 2010, 115:D16117.

53. Harrop BE, Hartmann DL. Testing the Role of Radiation in Determining Tropical Cloud-Top Temperature. Journal of Climate 2012, 25:5731-5747.

54. Tompkins AM, Craig GC. Sensitivity of tropical convection to sea surface temperature in the absence of large-scale flow. J. Climate 1999, 12:462-476.

55. Kuang Z, Hartmann DL. Testing the Fixed Anvil Temperature Hypothesis in a Cloud-Resolving Model. Journal of Climate 2007, 20:2051-2057.

56. Khairoutdinov M, Emanuel K. Rotating radiative-convective equilibrium simulated by a cloud-resolving model. Journal of Advances in Modeling Earth Systems 2013, 5:816-825.

57. Satoh M, Iga S-i, Tomita H, Tsushima Y, Noda AT. Response of Upper Clouds in Global Warming Experiments Obtained Using a Global Nonhydrostatic Model with Explicit Cloud Processes. Journal of Climate 2012, 25:2178-2191.

58. Tsushima Y, Iga S-i, Tomita H, Satoh M, Noda AT, Webb MJ. High cloud increase in a perturbed SST experiment with a global nonhydrostatic model including explicit convective processes. Journal of Advances in Modeling Earth Systems 2014, 6:571-585.

59. Bretherton CS, Blossey PN, Stan C. Cloud feedbacks on greenhouse warming in the superparameterized climate model SP-CCSM4. Journal of Advances in Modeling Earth Systems 2014, 6:1185-1204.

60. Li Y, Yang P, North GR, Dessler A. Test of the Fixed Anvil Temperature Hypothesis. Journal of the Atmospheric Sciences 2012, 69:2317-2328.

61. Zelinka MD, Hartmann DL. The observed sensitivity of high clouds to mean surface temperature anomalies in the tropics. Journal of Geophysical Research-Atmospheres 2011, 116.

62. Eitzen ZA, Xu KM, Wong T. Cloud and Radiative Characteristics of Tropical Deep Convective Systems in Extended Cloud Objects from CERES Observations. J. Climate 2009, 22:59836000.

63. Xu KM, Wong T, Wielicki BA, Parker L, Eitzen ZA. Statistical Analyses of Satellite Cloud Object

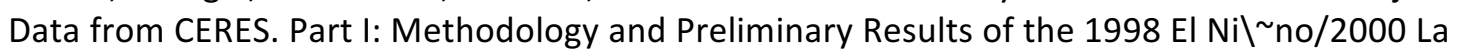
$\mathrm{Ni} \sim$ na. J. Climate 2005, 18:2497-2514.

64. Xu KM, Wong T, Wielicki BA, Parker L, Lin B, Eitzen ZA, Branson M. Statistical Analyses of Satellite Cloud Object Data from CERES. Part II: Tropical Convective Cloud Objects during $1998 \mathrm{El}$ Nino and Evidence for Supporting the Fixed Anvil Temperature Hypothesis. J. Climate 2007, 20:819-842.

65. Kubar TL, Hartmann DL, Wood R. Radiative and Convective Driving of Tropical High Clouds. J. Climate 2007, 20:5510-5526.

66. Norris JR, Allen RJ, Evan AT, Zelinka MD, O'Dell CW, Klein SA. Evidence for climate change in the satellite cloud record. Nature 2016, 536:72-75.

67. Marvel K, Zelinka M, Klein SA, Bonfils C, Caldwell P, Doutriaux C, Santer BD, Taylor KE. External Influences on Modeled and Observed Cloud Trends. Journal of Climate 2015, 28:4820-4840.

68. Wetherald RT, Manabe S. Cloud Feedback Processes in a General Circulation Model. Journal of the Atmospheric Sciences 1988, 45:1397-1416.

69. Santer BD, Sausen R, Wigley TML, Boyle JS, AchutaRao K, Doutriaux C, Hansen JE, MeehI GA, Roeckner $E$, Ruedy $R$, et al. Behavior of tropopause height and atmospheric temperature in 
models, reanalyses, and observations: Decadal changes. Journal of Geophysical ResearchAtmospheres 2003, 108.

70. Santer BD, Wehner MF, Wigley TML, Sausen R, Meehl GA, Taylor KE, Ammann C, Arblaster J, Washington WM, Boyle JS, et al. Contributions of anthropogenic and natural forcing to recent tropopause height changes. Science 2003, 301:479-483.

71. Fu Q, Manabe S, Johanson CM. On the warming in the tropical upper troposphere: Models versus observations. Geophysical Research Letters 2011, 38.

72. Mitchell DM, Thorne PW, Stott PA, Gray LJ. Revisiting the controversial issue of tropical tropospheric temperature trends. Geophysical Research Letters 2013, 40:2801-2806.

73. Zhang MH, Lin WY, Klein SA, Bacmeister JT, Bony S, Cederwall RT, Del Genio AD, Hack JJ, Loeb NG, Lohmann $U$, et al. Comparing clouds and their seasonal variations in 10 atmospheric general circulation models with satellite measurements. Journal of Geophysical Research-Atmospheres 2005, 110.

74. Williams K, Webb M. A quantitative performance assessment of cloud regimes in climate models. Climate Dyn. 2009, 33:141-157.

75. Tsushima Y, Ringer MA, Webb MJ, Williams KD. Quantitative evaluation of the seasonal variations in climate model cloud regimes. Climate Dynamics 2013, 41:2679-2696.

76. Blossey PN, Bretherton CS, Zhang M, Cheng A, Endo S, Heus T, Liu Y, Lock AP, de Roode SR, $\mathrm{Xu}$ K-M. Marine low cloud sensitivity to an idealized climate change: The CGILS LES intercomparison. Journal of Advances in Modeling Earth Systems 2013, 5:234-258.

77. Bretherton CS, Wyant MC. Moisture Transport, Lower-Tropospheric Stability, and Decoupling of Cloud-Topped Boundary Layers. Journal of the Atmospheric Sciences 1997, 54:148-167.

78. Klein SA, Hartmann DL. The Seasonal Cycle of Low Stratiform Clouds. Journal of Climate 1993, 6:1587-1606.

79. Wood R, Bretherton CS. On the Relationship between Stratiform Low Cloud Cover and Lower-Tropospheric Stability. Journal of Climate 2006, 19:6425-6432.

80. Qu X, Hall A, Klein SA, Caldwell PM. The strength of the tropical inversion and its response to climate change in 18 CMIP5 models. Climate Dynamics 2015, 45:375-396.

81. Miller RL. Tropical Thermostats and Low Cloud Cover. Journal of Climate 1997, 10:409-440.

82. Brient F, Bony S. Interpretation of the positive low-cloud feedback predicted by a climate model under global warming. Climate Dynamics 2013, 40:2415-2431.

83. Zhang M, Bretherton CS, Blossey PN, Austin PH, Bacmeister JT, Bony S, Brient F, Cheedela SK, Cheng $A$, Del Genio AD, et al. CGILS: Results from the first phase of an international project to understand the physical mechanisms of low cloud feedbacks in single column models. Journal of Advances in Modeling Earth Systems 2013, 5:826-842.

84. Myers TA, Norris JR. On the Relationships between Subtropical Clouds and Meteorology in Observations and CMIP3 and CMIP5 Models. Journal of Climate 2015, 28:2945-2967.

85. Albrecht BA, Jensen MP, Syrett WJ. Marine boundary layer structure and fractional cloudiness. Journal of Geophysical Research 1995, 100:14209-14209.

86. Myers TA, Norris JR. Observational Evidence That Enhanced Subsidence Reduces Subtropical Marine Boundary Layer Cloudiness. Journal of Climate 2013, 26:7507-7524.

87. Qu X, Hall A, Klein SA, DeAngelis AM. Positive tropical marine low-cloud cover feedback inferred from cloud-controlling factors. Geophysical Research Letters 2015, 42:7767-7775.

88. Vogel R, Nuijens L, Stevens B. The role of precipitation and spatial organization in the response of trade-wind clouds to warming. Journal of Advances in Modeling Earth Systems 2016, 8:843-862.

89. Tan Z, Schneider T, Teixeira J, Pressel KG. Large-eddy simulation of subtropical cloud-topped boundary layers: 1. A forcing framework with closed surface energy balance. Journal of Advances in Modeling Earth Systems 2016, 8:1565-1585. 
90. Tan Z, Schneider T, Teixeira J, Pressel KG. Large-eddy simulation of subtropical cloud-topped boundary layers: 2. Cloud response to climate change. Journal of Advances in Modeling Earth Systems 2017.

91. Wyant MC, Bretherton CS, Blossey PN. Subtropical Low Cloud Response to a Warmer Climate in a Superparameterized Climate Model. Part I: Regime Sorting and Physical Mechanisms. Journal of Advances in Modeling Earth Systems 2009, 1:n/a-n/a.

92. Qu X, Hall A, Klein SA, Caldwell PM. On the spread of changes in marine low cloud cover in climate model simulations of the 21st century. Climate Dynamics 2014, 42:2603-2626.

93. Brient F, Schneider T. Constraints on climate sensitivity from space-based measurements of low-cloud reflection. Journal of Climate 2016.

94. Myers TA, Norris JR. Reducing the uncertainty in subtropical cloud feedback. Geophysical Research Letters 2016, 43:2144-2148.

95. McCoy DT, Eastman R, Hartmann DL, Wood R. The change in low cloud cover in a warmed climate inferred from AIRS, MODIS and ECMWF-Interim reanalysis. Journal of Climate 2017:JCLI-D-15-0734.0731.

96. Nuijens L, Medeiros B, Sandu I, Ahlgrimm M. Observed and modeled patterns of covariability between low-level cloudiness and the structure of the trade-wind layer. Journal of Advances in Modeling Earth Systems 2015, 7:1741-1764.

97. Nuijens L, Medeiros B, Sandu I, Ahlgrimm M. The behavior of trade-wind cloudiness in observations and models: The major cloud components and their variability. Journal of Advances in Modeling Earth Systems 2015, 7:600-616.

98. Siebesma AP, Soares PMM, Teixeira J. A Combined Eddy-Diffusivity Mass-Flux Approach for the Convective Boundary Layer. Journal of the Atmospheric Sciences 2007, 64:1230-1248.

99. Larson VE, Schanen DP, Wang M, Ovchinnikov M, Ghan S. PDF Parameterization of Boundary Layer Clouds in Models with Horizontal Grid Spacings from 2 to $16 \mathrm{~km}$. Monthly Weather Review 2012, 140:285-306.

100. Medeiros B, Stevens B, Bony S. Using aquaplanets to understand the robust responses of comprehensive climate models to forcing. Climate Dynamics 2015.

101. Neggers RAJ. Attributing the behavior of low-level clouds in large-scale models to sub-grid scale parameterizations. Journal of Advances in Modeling Earth Systems 2015, 7:2029-2043.

102. Geoffroy O, Sherwood S, Fuchs D. On the role of the stratiform cloud scheme in the intermodel spread of cloud feedback. Journal of Advances in Modeling Earth Systems 2017.

103. Watanabe $M$, Shiogama H, Yokohata T, Kamae $Y$, Yoshimori M, Ogura T, Annan JD, Hargreaves JC, Emori S, Kimoto M. Using a Multiphysics Ensemble for Exploring Diversity in Cloud-Shortwave Feedback in GCMs. Journal of Climate 2012, 25:5416-5431.

104. Kamae Y, Shiogama H, Watanabe M, Ogura T, Yokohata T, Kimoto M. Lower-Tropospheric Mixing as a Constraint on Cloud Feedback in a Multiparameter Multiphysics Ensemble. Journal of Climate 2016, 29:6259-6275.

105. Gettelman A, Kay JE, Shell KM. The Evolution of Climate Sensitivity and Climate Feedbacks in the Community Atmosphere Model. Journal of Climate 2012, 25:1453-1469.

106. Zhao M. An Investigation of the Connections among Convection, Clouds, and Climate Sensitivity in a Global Climate Model. Journal of Climate 2014, 27:1845-1862.

107. Zhao M, Golaz JC, Held IM, Ramaswamy V, Lin SJ, Ming Y, Ginoux P, Wyman B, Donner LJ, Paynter D, et al. Uncertainty in Model Climate Sensitivity Traced to Representations of Cumulus Precipitation Microphysics. Journal of Climate 2016, 29:543-560.

108. Tomassini L, Voigt A, Stevens B. On the connection between tropical circulation, convective mixing, and climate sensitivity. Quarterly Journal of the Royal Meteorological Society 2015, 141:1404-1416.

109. Sherwood SC, Bony S, Dufresne J-L. Spread in model climate sensitivity traced to atmospheric convective mixing. Nature 2014, 505:37-42. 
110. Vial J, Bony S, Dufresne J-L, Roehrig R. Coupling between lower-tropospheric convective mixing and low-level clouds: Physical mechanisms and dependence on convection scheme. Journal of Advances in Modeling Earth Systems 2016.

111. Webb MJ, Lock AP, Bretherton CS, Bony S, Cole JNS, Idelkadi A, Kang SM, Koshiro T, Kawai H, Ogura T, et al. The impact of parametrized convection on cloud feedback. Philosophical transactions. Series A, Mathematical, physical, and engineering sciences 2015, 373.

112. Kawai H. Examples of Mechanisms for Negative Cloud Feedback of Stratocumulus and Stratus in Cloud Parameterizations. SOLA 2012, 8:150-154.

113. Zhang $M$, Bretherton C. Mechanisms of Low Cloud-Climate Feedback in Idealized SingleColumn Simulations with the Community Atmospheric Model, Version 3 (CAM3). Journal of Climate 2008, 21:4859-4878.

114. Stephens GL. Radiation Profiles in Extended Water Clouds. II: Parameterization Schemes. Journal of the Atmospheric Sciences 1978, 35:2123-2132.

115. Pruppacher HR, Klett JD. Microphysics of Clouds and Precipitation. 2010, 18:954.

116. McCoy DT, Hartmann DL, Zelinka MD, Ceppi P, Grosvenor DP. Mixed-phase cloud physics and Southern Ocean cloud feedback in climate models. Journal of Geophysical Research: Atmospheres 2015, 120:9539-9554.

117. Tsushima Y, Emori S, Ogura T, Kimoto M, Webb MJ, Williams KD, Ringer MA, Soden BJ, Li B, Andronova N. Importance of the mixed-phase cloud distribution in the control climate for assessing the response of clouds to carbon dioxide increase: a multi-model study. Climate Dynamics 2006, 27:113-126.

118. Betts AK, Harshvardhan. Thermodynamic constraint on the cloud liquid water feedback in climate models. Journal of Geophysical Research 1987, 92:8483.

119. Klein SA, McCoy RB, Morrison H, Ackerman AS, Avramov A, Boer Gd, Chen M, Cole JNS, Del Genio $A D$, Falk $M$, et al. Intercomparison of model simulations of mixed-phase clouds observed during the ARM Mixed-Phase Arctic Cloud Experiment. I: single-layer cloud. Quarterly Journal of the Royal Meteorological Society 2009, 135:979-1002.

120. Tselioudis G, Rossow WB, Rind D. Global Patterns of Cloud Optical Thickness Variation with Temperature. Journal of Climate 1992, 5:1484-1495.

121. Storelvmo T, Tan I, Korolev AV. Cloud Phase Changes Induced by CO2 Warming - a Powerful yet Poorly Constrained Cloud-Climate Feedback. Current Climate Change Reports 2015, 1:288-296.

122. DeMott PJ, Prenni AJ, Liu X, Kreidenweis SM, Petters MD, Twohy CH, Richardson MS, Eidhammer T, Rogers DC. Predicting global atmospheric ice nuclei distributions and their impacts on climate. Proceedings of the National Academy of Sciences 2010, 107:1121711222.

123. Terai CR, Klein SA, Zelinka MD. Constraining the low-cloud optical depth feedback at middle and high latitudes using satellite observations. Journal of Geophysical Research: Atmospheres 2016, 121:9696-9716.

124. Somerville RCJ, Remer LA. Cloud optical thickness feedbacks in the $\mathrm{CO} 2$ climate problem. Journal of Geophysical Research 1984, 89:9668.

125. Paltridge GW. Cloud-radiation feedback to climate. Quarterly Journal of the Royal Meteorological Society 1980, 106:895-899.

126. Mitchell JFB, Senior CA, Ingram WJ. CO2 and climate: a missing feedback? Nature 1989, 341:132-134.

127. Findeisen W. Die kolloidmeteorologischen Vorgänge bei Niederschlagsbildung. Meteorologische Zeitschrift 1938, 55:121-133.

128. Storelvmo T, Tan I. The Wegener-Bergeron-Findeisen process - Its discovery and vital importance for weather and climate. Meteorologische Zeitschrift 2015.

129. Senior CA, Mitchell JFB. Carbon Dioxide and Climate. The Impact of Cloud Parameterization. Journal of Climate 1993, 6:393-418. 
130. Choi Y-S, Ho C-H, Park C-E, Storelvmo T, Tan I. Influence of cloud phase composition on climate feedbacks. Journal of Geophysical Research: Atmospheres 2014, 119:3687-3700.

131. Li Z-X, Le Treut H. Cloud-radiation feedbacks in a general circulation model and their dependence on cloud modelling assumptions. Climate Dynamics 1992, 7:133-139.

132. Kay JE, Bourdages L, Miller NB, Morrison A, Yettella V, Chepfer H, Eaton B. Evaluating and improving cloud phase in the Community Atmosphere Model version 5 using spaceborne lidar observations. Journal of Geophysical Research: Atmospheres 2016, 121:4162-4176.

133. Tan I, Storelvmo T, Zelinka MD. Observational constraints on mixed-phase clouds imply higher climate sensitivity. Science 2016, 352:224-227.

134. DeMott PJ, Möhler O, Stetzer O, Vali G, Levin Z, Petters MD, Murakami M, Leisner T, Bundke $\mathrm{U}, \mathrm{Klein} \mathrm{H}$, et al. Resurgence in Ice Nuclei Measurement Research. Bulletin of the American Meteorological Society 2011, 92:1623-1635.

135. Gettelman A, Liu X, Barahona D, Lohmann U, Chen C. Climate impacts of ice nucleation. Journal of Geophysical Research: Atmospheres 2012, 117:n/a-n/a.

136. Hu Y, Rodier S, Xu K-m, Sun W, Huang J, Lin B, Zhai P, Josset D. Occurrence, liquid water content, and fraction of supercooled water clouds from combined CALIOP/IIR/MODIS measurements. Journal of Geophysical Research 2010, 115:D00H34.

137. Komurcu M, Storelvmo T, Tan I, Lohmann U, Yun Y, Penner JE, Wang Y, Liu X, Takemura T. Intercomparison of the cloud water phase among global climate models. Journal of Geophysical Research: Atmospheres 2014, 119:3372-3400.

138. Cesana G, Waliser DE, Jiang X, Li J-LF. Multi-model evaluation of cloud phase transition using satellite and reanalysis data. Journal of Geophysical Research: Atmospheres 2015, 120.

139. McCoy DT, Tan I, Hartmann DL, Zelinka MD, Storelvmo T. On the relationships among cloud cover, mixed-phase partitioning, and planetary albedo in GCMs. Journal of Advances in Modeling Earth Systems 2016, 8:1-19.

140. Bodas-Salcedo A, Andrews T, Karmalkar AV, Ringer MA. Cloud liquid water path and radiative feedbacks over the Southern Ocean. Geophysical Research Letters 2016.

141. Bony S, Dufresne J-L, Le Treut H, Morcrette J-J, Senior C. On dynamic and thermodynamic components of cloud changes. Climate Dynamics 2004, 22:71-86.

142. Shepherd TG. Atmospheric circulation as a source of uncertainty in climate change projections. Nature Geoscience 2014, 7:703-708.

143. Hartmann DL, Short DA. On the Use of Earth Radiation Budget Statistics for Studies of Clouds and Climate. Journal of the Atmospheric Sciences 1980, 37:1233-1250.

144. Ramanathan V, Cess RD, Harrison EF, Minnis P, Barkstrom BR, Ahmad E, Hartmann D. CloudRadiative Forcing and Climate: Results from the Earth Radiation Budget Experiment. Science 1989, 243.

145. Harrison EF, Minnis P, Barkstrom BR, Ramanathan V, Cess RD, Gibson GG. Seasonal variation of cloud radiative forcing derived from the Earth Radiation Budget Experiment. Journal of Geophysical Research 1990, 95:18687-18687.

146. Hartmann DL, Moy LA, Fu Q. Tropical Convection and the Energy Balance at the Top of the Atmosphere. Journal of Climate 2001, 14:4495-4511.

147. Lindzen RS, Chou M-D, Hou AY. Does the Earth Have an Adaptive Infrared Iris? Bulletin of the American Meteorological Society 2001, 82:417-432.

148. Hartmann DL, Michelsen ML. No Evidence for Iris. Bulletin of the American Meteorological Society 2002, 83:249-254.

149. Fu Q, Baker M, Hartmann DL. Tropical cirrus and water vapor: an effective Earth infrared iris feedback? Atmospheric Chemistry and Physics 2002, 2:31-37.

150. Chambers LH, Lin B, Young DF. Examination of New CERES Data for Evidence of Tropical Iris Feedback. Journal of Climate 2002, 15:3719-3726.

151. Lin B, Wielicki BA, Chambers LH, Hu Y, Xu K-M. The Iris Hypothesis: A Negative or Positive Cloud Feedback? Journal of Climate 2002, 15:3-7. 
152. Mauritsen T, Stevens B. Missing iris effect as a possible cause of muted hydrological change and high climate sensitivity in models. Nature Geoscience 2015, 8:346-351.

153. Mitchell JFB, Wilson CA, Cunnington WM. On CO2 climate sensitivity and model dependence of results. Quarterly Journal of the Royal Meteorological Society 1987, 113:293-322.

154. Su H, Bretherton CS, Chen SS. Self-Aggregation and Large-Scale Control of Tropical Deep Convection: A Modeling Study. Journal of the Atmospheric Sciences 2000, 57:1797-1816.

155. Bretherton CS, Blossey PN, Khairoutdinov M. An Energy-Balance Analysis of Deep Convective Self-Aggregation above Uniform SST. Journal of the Atmospheric Sciences 2005, 62:42734292.

156. Wing AA, Emanuel KA. Physical mechanisms controlling self-aggregation of convection in idealized numerical modeling simulations. Journal of Advances in Modeling Earth Systems 2014, 6:59-74.

157. Bony S, Colman R, Kattsov VM, Allan RP, Bretherton CS, Dufresne J-L, Hall A, Hallegatte S, Holland MM, Ingram W, et al. How Well Do We Understand and Evaluate Climate Change Feedback Processes? Journal of Climate 2006, 19:3445-3482.

158. Barnes EA, Polvani L. Response of the midlatitude jets and of their variability to increased greenhouse gases in the CMIP5 models. Journal of Climate 2013, 26:7117-7135.

159. Bender FA-M, Ramanathan V, Tselioudis G. Changes in extratropical storm track cloudiness 1983-2008: observational support for a poleward shift. Climate Dynamics 2012, 38:20372053.

160. Grise KM, Polvani LM, Tselioudis G, Wu Y, Zelinka MD. The ozone hole indirect effect: Cloudradiative anomalies accompanying the poleward shift of the eddy-driven jet in the Southern Hemisphere. Geophysical Research Letters 2013, 40:3688-3692.

161. Ceppi P, Zelinka MD, Hartmann DL. The response of the Southern Hemispheric eddy-driven jet to future changes in shortwave radiation in CMIP5. Geophysical Research Letters 2014, 41:3244-3250.

162. Kay JE, Medeiros B, Hwang YT, Gettelman A, Perket J, Flanner MG. Processes controlling Southern Ocean Shortwave Climate Feedbacks in CESM. Geophysical Research Letters 2014, 41:616-622.

163. Wall CJ, Hartmann DL. On the influence of poleward jet shift on shortwave cloud feedback in global climate models. Journal of Advances in Modeling Earth Systems 2015, 7:2044-2059.

164. Li Y, Thompson DWJ, Huang $Y$, Zhang M. Observed linkages between the northern annular mode/North Atlantic Oscillation, cloud incidence, and cloud radiative forcing. Geophysical Research Letters 2014, 41:1681-1688.

165. Tselioudis G, Lipat BR, Konsta D, Grise KM, Polvani LM. Midlatitude cloud shifts, their primary link to the Hadley cell, and their diverse radiative effects. Geophysical Research Letters 2016, 43:4594-4601.

166. Randall D, Khairoutdinov M, Arakawa A, Grabowski W. Breaking the Cloud Parameterization Deadlock. Bulletin of the American Meteorological Society 2003, 84:1547-1564.

167. Grabowski WW, Smolarkiewicz PK. CRCP: a Cloud Resolving Convection Parameterization for modeling the tropical convecting atmosphere. Physica D: Nonlinear Phenomena 1999, 133:171-178.

168. Khairoutdinov MF, Randall DA. A cloud resolving model as a cloud parameterization in the NCAR Community Climate System Model: Preliminary results. Geophysical Research Letters 2001, 28:3617-3620.

169. Grabowski WW. Towards Global Large Eddy Simulation: Super-Parameterization Revisited. Journal of the Meteorological Society of Japan 2016, 94:327-344.

170. Gettelman A, Sherwood SC. Processes Responsible for Cloud Feedback. Current Climate Change Reports 2016:1-11.

171. Herbert RJ, Murray BJ, Dobbie SJ, Koop T. Sensitivity of liquid clouds to homogenous freezing parameterizations. Geophysical Research Letters 2015, 42:1599-1605. 
172. Ceppi P, Hartmann DL. Clouds and the atmospheric circulation response to warming. Journal of Climate 2016, 29:783-799.

173. Shaw TA, Baldwin M, Barnes EA, Caballero R, Garfinkel Cl, Hwang YT, Li C, O'Gorman PA, Rivière $G$, Simpson IR, et al. Storm track processes and the opposing influences of climate change. Nature Geoscience 2016, 9:656-664.

174. Bony S, Stevens B, Frierson DMW, Jakob C, Kageyama M, Pincus R, Shepherd TG, Sherwood $\mathrm{SC}$, Siebesma AP, Sobel AH, et al. Clouds, circulation and climate sensitivity. Nature Geoscience 2015, 8:261-268.

175. Webb MJ, Andrews T, Bodas-Salcedo A, Bony S, Bretherton CS, Chadwick R, Chepfer H, Douville H, Good P, Kay JE, et al. The Cloud Feedback Model Intercomparison Project (CFMIP) contribution to CMIP6. Geoscientific Model Development 2017, 10:359-384.

176. Winton M, Takahashi K, Held IM. Importance of Ocean Heat Uptake Efficacy to Transient Climate Change. Journal of Climate 2010, 23:2333-2344.

177. Armour KC, Bitz CM, Roe GH. Time-Varying Climate Sensitivity from Regional Feedbacks. Journal of Climate 2013, 26:4518-4534.

178. Rose BEJ, Armour KC, Battisti DS, Feldl N, Koll DDB. The dependence of transient climate sensitivity and radiative feedbacks on the spatial pattern of ocean heat uptake. Geophysical Research Letters 2014, 41:1071-1078.

179. Andrews T, Gregory JM, Webb MJ. The Dependence of Radiative Forcing and Feedback on Evolving Patterns of Surface Temperature Change in Climate Models. Journal of Climate 2015, 28:1630-1648.

180. Gregory JM, Andrews T. Variation in climate sensitivity and feedback parameters during the historical period. Geophysical Research Letters 2016, 43:3911-3920.

181. Zhou C, Zelinka MD, Klein SA. Impact of decadal cloud variations on the Earth's energy budget. Nature Geoscience 2016, 9:871-874. 